3

\title{
DURABILITY OF CONCRETE WITH ELECTRIC ARC FURNACE SLAG
}

AGGREGATE

\author{
M.A. González-Ortega ${ }^{a}$, S.H.P. Cavalaro ${ }^{b}$, G. Rodríguez de Sensale ${ }^{c^{*}}$, A. Aguado $^{a}$
}

a. Universitat Politècnica de Catalunya (UPC), Department of Civil and Environmental Engineering, Jordi Girona 1-3,

C1, 08034 Barcelona, Spain

b. Loughborough University, School of Architecture, Building and Civil Engineering, Sir Frank Gibb Building RT102, Loughborough, United Kingdom

c. Universidad de la República (UdelaR), Facultad de Arquitectura-Facultad de Ingeniería, Edil Hugo Prato 2314, CP 11200 Montevideo, Uruguay

ABSTRACT:

The durability of concrete mixes with EAF slag as aggregate (HS) is studied; mixes with limestone $(\mathrm{HC})$ and barite $(\mathrm{HAB})$ aggregates were used as reference for structural and heavy-weight applications, respectively. Compressive strength, elastic modulus, water penetration under pressure, wet-dry cycles, freeze-thaw cycles, influence of environmental condition and leaching tests were conducted. The results indicate that HS tends to present higher depth of water penetration under pressure, a slightly higher expansion, higher carbonation depth and similar compressive strength than reference HC. Should be payed attention to the formation of stain points on HS concrete surface subjected to wet-drying cycles.

\section{KEYWORDS:}

EAF slag, Durability, Concrete, Wetting-drying cycles, Freeze-thaw, Leaching

Corresponding author.

E-mail address: gemma@fing.edu.uy (G. Rodríguez de Sensale) 
The production of steel generates a by-product (slag) that has been incorporated in the construction industry to reduce the environmental impact. In this context, several slag types derived from steel production may be listed: blast furnace slag (BFS), electric arc-furnace oxidizing slag (EAF), ladle-furnace basic slag (LFS), etc. According to the World Steel Association, world crude steel production has increased from $849 \mathrm{Mt}$ in 2000 [1] to $1690 \mathrm{Mt}$ for the year 2018 [2]. Electric arc furnaces are responsible for around $28 \%$ of the global production in the world [2]. Due to the high amount of EAF slag generated, its use in the construction civil is explored in the literature $[1,9]$ and studies about its application have also been conducted by research groups throughout the world. Untreated EAF slag was applied in bases and sub-bases of road pavements [9-11]. Studies demonstrated the viability of including the EAF slag as an aggregate in bituminous pavement $[10,12-$ 14]. More recent studies focused on including EAF slag as an aggregate for concrete without structural responsibility. In the majority of cases, the authors used EAF Slag previously subjected to weathering and/or irrigation with water to reduce the amount of potentially expansive compounds present in the material. A large number of possible concrete dosages achieved by replacing limestone aggregate by EAF slag aggregate were tested. The partial substitution of the fine fraction (sand) was evaluated in [1519], the partial substitution of the coarse fraction was evaluated in $[15,16,19,20-30]$ and a total replacement of both fractions was assessed in [30-35]. Other authors used a combination of EAF slag and white slag $[9,36]$, air-entraining agents $[24,27]$, alkaline activators or mineral admixtures such as fly ash and silica fume [22, 37-39]. The first application of concrete with EAF slag with structural responsibility in Spain was in the "KUBIK" building in Basque Country as a result of the work by Arribas [31]. This is one of the very few examples that may be found worldwide. The scarce use of this material in applications with structural responsibility is a direct consequence of uncertainties regarding the durability and dimensional stability of the material over time. In comparison with what may be found in the literature for other types of concrete, a limited number of studies have addressed the durability and long-term performance of concrete with EAF slag $[3,4,15,16,24,25,30,34-36,38,40-45]$. 
57 Slag was lower than in conventional concrete; the absorption decreased as the substitution of limestone coarse aggregate by EAF Slag increased; the results for the accelerated aging according to ASTM D-4792 showed different trends. Water absorption by surface capillarity, on EAF concrete specimens with and without fibers moist-cured for 90 days, was studied in a recent paper by Ortega-López et al [44]. The higher permeability of mixes with EAF without fibers was coherent with the distribution of pores measured by Mercury Intrusion Porosimetry (MIP), in the case $0.1 \mu \mathrm{m}$, being the pore size more favorable for water diffusion. Santamaría et al [45] observed that mixes containing EAFS showed better resistance to water penetration under pressure than concrete mixes made with natural aggregates. According to Sezer and Gülderen [16], water penetration depth under pressure test of concrete specimens with EAF slag used as coarse aggregate was lower, while using it as fine aggregate was higher, when compared to control concrete mixtures containing limestone aggregate. Arribas [31] evaluated the corrosion of steel bars embedded in concrete with EAF slag, which was exposed to marine environment for one year; a similar behavior was found between these specimens and the reference ones made with limestone aggregate. According to results of studies recently published by Santamaria et al [45], following the specifications of the ASTM C-876 standard, the electrochemical corrosion rates of steel rebars embedded in conventional concrete clearly showed a gradual evolution that was more detrimental than the corrosion rates of mixes made with EAF aggregates; the lixiviation of Ca-ions to the cementitious matrix due to the presence of free- $\mathrm{CaO}$ in the slag, can be considered very positively in relation to the long-term preservation of steel reinforcements. Amaral [15] evaluated the carbonation depth in specimens under accelerated carbonation test (climatic chamber with $65 \%$ relative humidity and $\mathrm{CO}_{2}$ saturated atmosphere) and specimens exposed to laboratory condition for one year. Mixes with the substitution of the traditional fine aggregates by EAF slag presented lower carbonation depths, whereas mixes with the substitution of the coarse aggregate presented higher penetration depths than the assessed for reference concrete. observed that specimens with EAF slag presented a greater reduction in compressive strength than those with conventional aggregate. Results of 122 freezing-thawing cycles were presented by Santamaria et al [45] concluding that the additional porosity provided by EAFS to global concrete does 
not favor this kind of durability. Pellegrino [27] and Polanco et al. [34] identified small reductions of the compressive strength of concrete with EAF slag after the freeze-thaw cycles. Conversely, Arribas et al. [40] observed an increase in the compressive strength of concrete samples with EAF slag subjected to freeze-thaw cycles. According to Sezer and Gülderen [16], higher freeze-thaw resistance was observed in concrete mixtures containing EAF as coarse aggregate and lower in concrete mixtures containing EAF slag as fine aggregate, when compared to control concrete mixtures using limestone aggregate.

Regarding the behavior under wet-dry cycles, Polanco et al. [34] identified a $6.9 \%$ increase in the compressive strength with small variation in weight and in the aesthetics of the samples. The alkaliaggregate reactivity was studied according to the procedure established in UNE 146508:1999 EX. Manso [32] concluded that EAF slag was not reactive. Arribas et al. [42] observed that the aggregate could be potentially reactive based on the results at 14 days. However, considering the results obtained at 28 days, a low reactivity level was identified.

The potential contamination from concrete with EAF slag was evaluated in $[15,31,42]$ through monolithic leaching tests. Amaral [15] observed a slight leaching of Ba. Arribas [31] observed that Ba and $\mathrm{V}$ values were close to the minimum detection levels, whereas the leached contents of $\mathrm{SO}_{4}{ }^{-2}$ and $\mathrm{Cl}^{-}$ increased during the test. Simulations performed by Arribas [31] based on the results of the tests considering a life of 100 years suggest that the total content released would be well below the established limits. Manso [32] concluded that concrete with EAF Slag can be safely used in construction.

Despite the important contribution of previous work, additional studies are still needed to provide solid evidence on the long-term performance of concrete with EAF slag [3]. Moreover, the comparison with other types of concrete depending on the application is also required. Notice that the majority of studies from the literature take conventional limestone aggregate as a reference. However, studies demonstrated the viability of using EAF slag as an aggregate for concrete in radioactive shielding applications or in applications that demand high density [46, 47-49]. In these cases, the reference of comparison should not be the limestone aggregate but the barite aggregate.

There are mainly two types of EAF slag aggregates identified in the literature [45]: one formed by higher oxides of iron content, with low porosity and high density $[20,50,51]$; another formed by lower oxides of iron content and lower density. In this paper the second type of slag is used. 

contamination of concrete with EAF slag in comparison with equivalent mixes with limestone (reference for typical structural applications) or barite aggregates (reference for heavy-weight or shielding applications). First, mixes were produced and tested for basic properties in fresh and hardened state.

117 Then, indirect (penetration of water under pressure) and direct tests (wet-dry cycles, freeze-thaw cycles and influence of environmental condition) were conducted to evaluate the durability under different exposure conditions for a period up to 3 years. Furthermore, leaching tests were conducted to assess the potential contamination of concrete. The conclusions of this paper are only valid for the EAF slag used, but the results derived from this study may promote the safe and efficient use of EAF slag in structural concrete. They also enhance the knowledge about the material, contribute to the state of the art and might support the development of guidelines and future standards.

\section{EXPERIMENTAL PROGRAM}

\subsection{Materials and mixes}

To compare the behavior in the case of EAF aggregates with alternative ones used in conventional concrete or in heavyweight concrete, were used limestone and barite aggregates. Table 1 shows the characteristics of all aggregates used in the experimental program in terms of maximum size, density and water absorption. The same table shows the chemical composition of the EAF slag used. The density of the EAF slag used (between 3310 and $3570 \mathrm{~kg} / \mathrm{m}^{3}$ ) is comparable to that of aggregates used to produce heavyweight concrete[47-49]. The limestone aggregate is considered the reference for normal and high-strength concrete; the barite aggregate is considered the reference for heavyweight concrete. The EAF slag was supplied by ArcelorMittal, a steel factory in Zaragoza (Spain); the limestone aggregate was extracted from a quarry in Palleja, Barcelona; and the barite was supplied by Mineralia Minerals Girona S.A. quarry in Spain. 


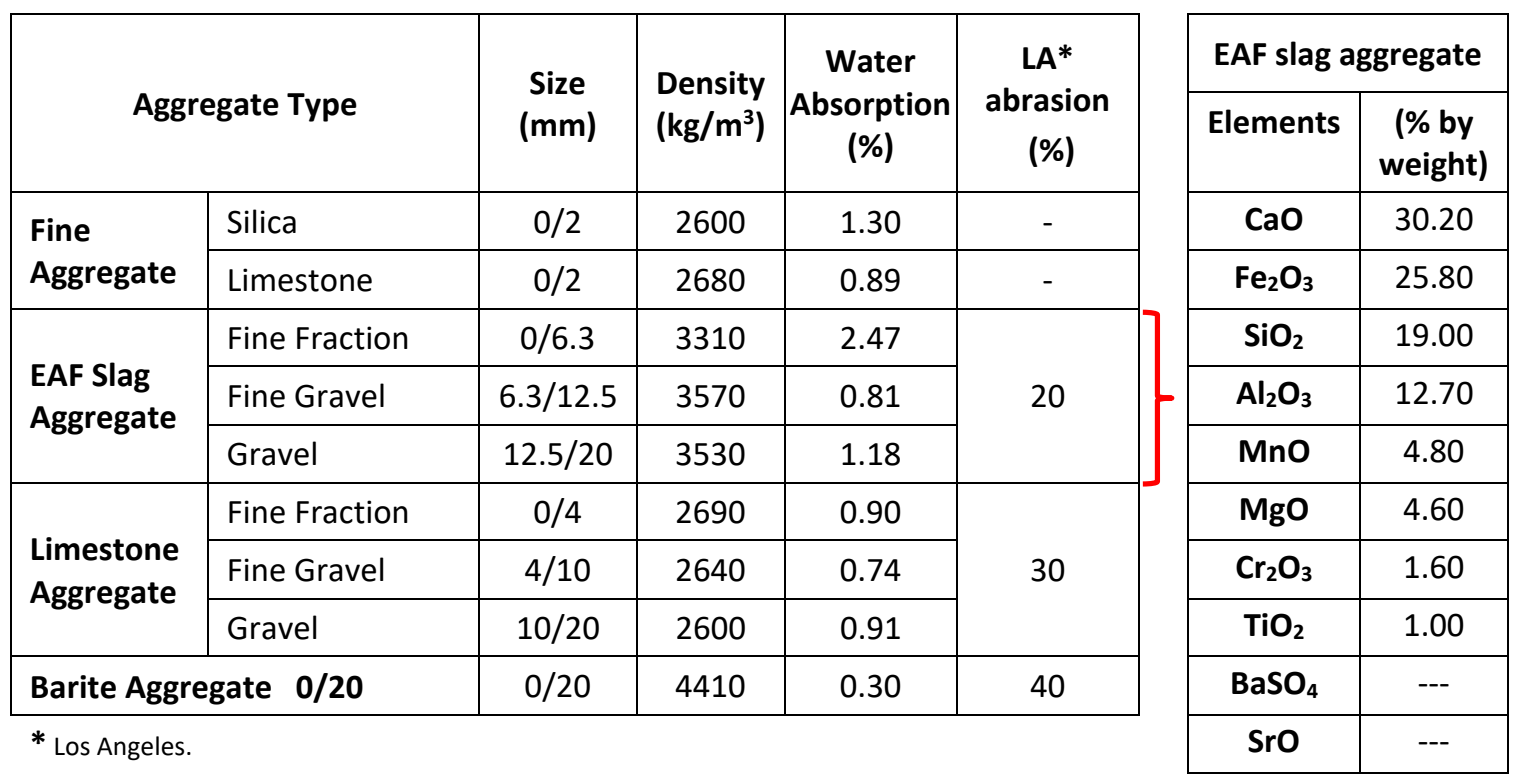

The barite grading ranges from 0 to $20 \mathrm{~mm}$ (0/20 according to the adopted notation), but

144 several EAF aggregate size ranges (0 / 6.3, 6.3 / 12.5 and $12.5 / 20)$ and the limestone $(0 / 2,0 / 4,4 / 10$

145 and 10/20) were mixed to compose classification curves that approximated to the barite curve. The

146 objective was to avoid introducing additional variables to the geologic nature of the aggregate, which

147 could hinder the comparison of the results. Figure 1 shows the global mix grading curve of the concrete

148 agreggates in accordance with EN 933-1:2012 [52]; in general similar curves are obtained, but small

149 differences appear for grading sizes between $0.2 \mathrm{~mm}$ and $1 \mathrm{~mm}$.

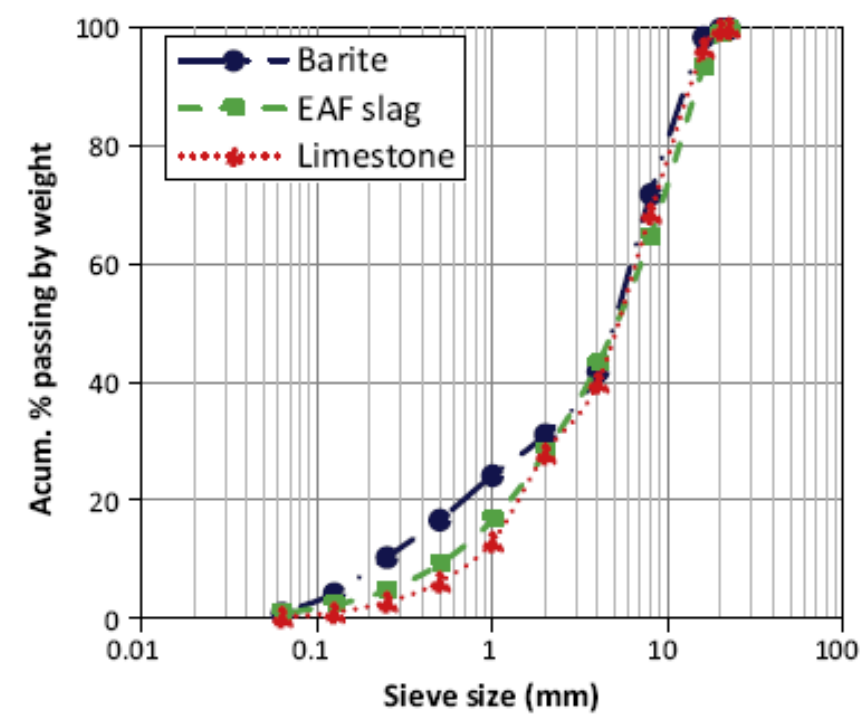



agregates (silica and limestone sand with particle sizes ranging from 0 to $2 \mathrm{~mm}$ ) were used as correctors. The fineness modulus of the fine aggregates are 1.92 and 1.98 units for the siliceous and limestones, respectively. lower oxides of iron content than EAF slags from Italy, China and Taiwan [30, 50, 51]. Iron nodules and unreacted calcium and magnesium oxides present in EAF slag are the main responsible for the potential expansion of the aggregate [45]. In contact with water, the calcium oxide hydrates, producing a rapid volumetric expansion. Santa Maria et al [45] provides quantitative evidence on the effects of slag pretreatment to reduce its swelling potential. In the long term, the hydration of magnesium oxide [35, 53-55] takes place, leading to additional expansions. The oxidation of iron spots embedded in the aggregate may also generate expansions and corrosion products. If the aggregate is embedded in a rigid matrix, the expansion may cause cracks and compromise the durability of the composite. To mitigate this negative effect, the EAF slag is usually subjected to weathering and/or irrigation with water prior application. The EAF slag used in this study also underwent such treatment. For further information on the treatment of the EAF slag and the grading curve of the aggregates, please consult [49].

Table 2 shows the six concrete mixes produced for the experimental program that included a conventional concrete with limestone aggregate $(\mathrm{HC})$, a heavy-weight concrete with barite aggregate ( $\mathrm{HAB}$ ) and four concrete mixes with complete substitution of the coarse aggregate and partial substitution of fine aggregate by EAF slag (HS). The six concrete mixes used are the same presented in González-Ortega et al [49]; due to the density of the EAF slag, comparable to that of aggregates used to produce heavyweight concrete, the HS mixtures correspond to concretes with structural responsibility that have a density of $2800 \mathrm{~kg} / \mathrm{m} 3$ approximately. According to the results presented in the cited document, these concrete mixtures could be used to analyze the durability of concretes with EAF aggregate. present in the latter. Mixes named HSS and HSC presented siliceous and limestone correcting sand, respectively. 


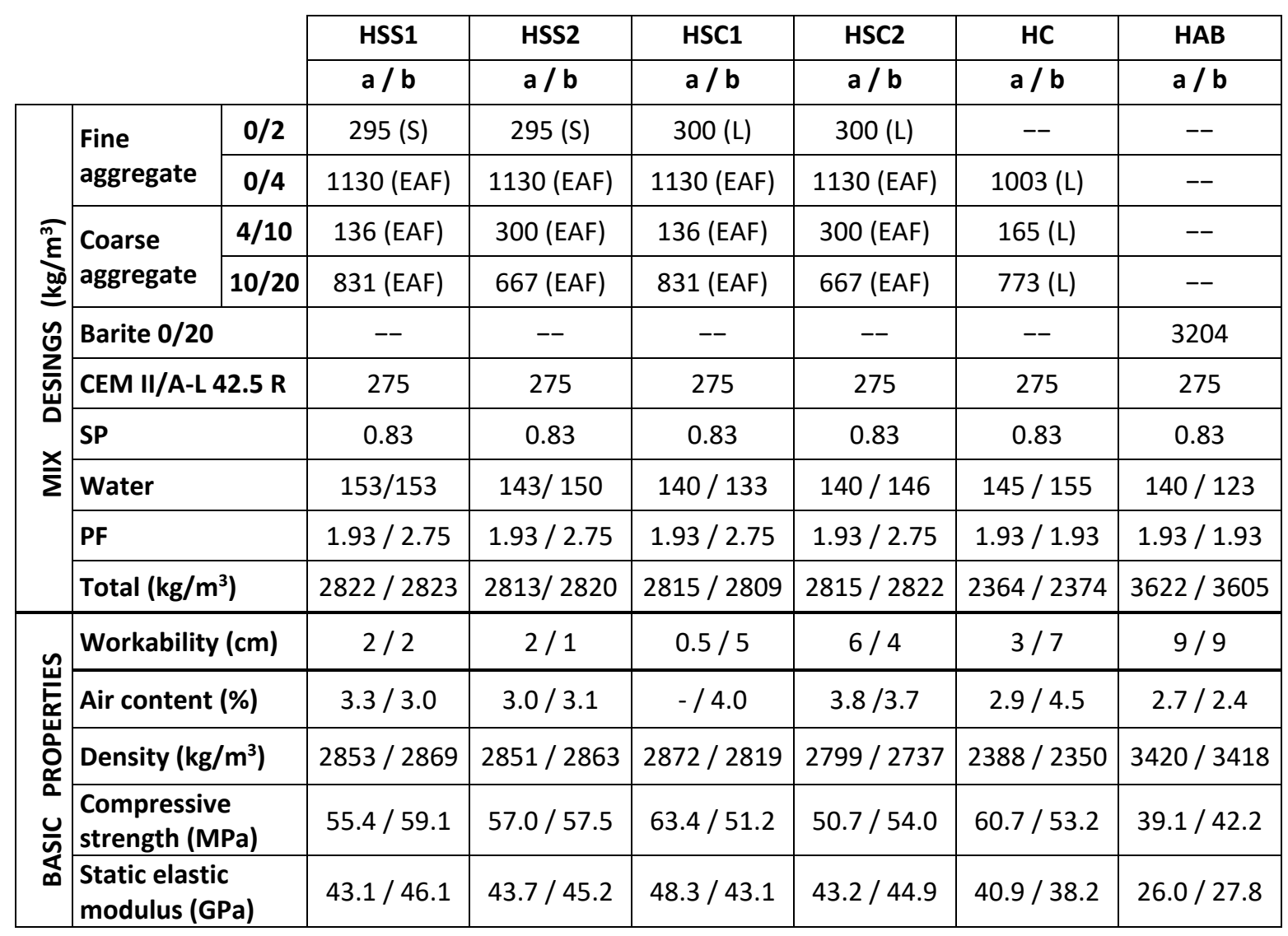

*(S)-Sílica; (L)-Limestone; (EAF)-EAF steel slags

A number was appended to the end of the nomenclature to indicate the proportion between

the two grading that compose the EAF slag. Mixes with the number 2 present a higher content of grading $4 / 10$ and lower content of grading 10/20 than mixes with the number 1 . These changes were made to evaluate the influence on the granular skeleton in the properties of concrete with EAF slag. A polycarboxylate superplasticizer (Viscocrete 5940, named SP) and a polyfunctional plasticizer (Melcrete PF-75, named PF) were used in all mixes. The letters " $a$ " or " $b$ " were appended to the nomenclature to indicate adjustments made in the water/cement ratio $(\mathrm{w} / \mathrm{c})$ and an increase in the admixture content. Except for $\mathrm{HC}$ and $\mathrm{HAB}, \mathrm{HS}$ mixes with the letter " $\mathrm{b}$ " presented higher admixture content than mixes with the letter "a". produce all specimens. Approximately 24 hours after production, specimens were demolded and kept in a curing chamber submerged in water until the date of testing. 


\section{$2.2 \quad$ Test methods}

\begin{tabular}{|c|c|c|c|c|}
\hline & Tests & Standard & $\begin{array}{c}\text { Specimen shape } \\
\text { and size }(\mathrm{cm})\end{array}$ & $\begin{array}{l}\text { Specimens } \\
\text { age (days) }\end{array}$ \\
\hline \multirow{5}{*}{ 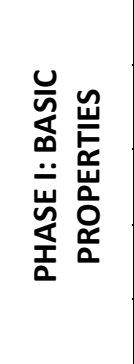 } & Workability & EN 12350-2:2009 [56] & \multirow{2}{*}{ Fresh } & \multirow{2}{*}{--} \\
\hline & Air content & EN 83315:1996[57] & & \\
\hline & Density & EN 12390-7:2009 [58] & \multirow{4}{*}{$\begin{array}{l}\text { Cylindrical } \\
15 \times 30\end{array}$} & 28 \\
\hline & Compressive strength & EN 12390-3:2009 [59] & & \\
\hline & Static modulus of elasticity & EN 12390-13:2014 [60] & & 30 \\
\hline \multirow{5}{*}{ 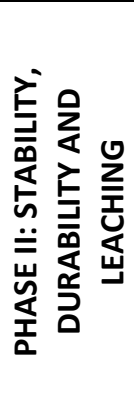 } & $\begin{array}{c}\text { Depth of water penetration } \\
\text { under pressure }\end{array}$ & EN 12390-8:2009 [61] & & 28 \\
\hline & Wetting-drying cycles & - & \multirow{2}{*}{$\begin{array}{l}\text { Cubic } 10 \times 10 \\
\text { Slabs } 20 \times 30 \times 5\end{array}$} & 117 \\
\hline & $\begin{array}{c}\text { Environmental influence } \\
\text { exposure }\end{array}$ & - & & \multirow{3}{*}{3 years } \\
\hline & Freeze-thaw cycles & - & Cylindrical 15x15 & \\
\hline & Leaching & NEN 7345:2004 [62] & Cylindrical 10x10 & \\
\hline
\end{tabular}
certain behaviors of the next phase; the second phase included the tests to evaluate the long-term performance which is the objective of this work. The tests, the standards, the shape of the specimens used and the age of characterization are presented in Table 3. The result of each test represents the average between 2 and 4 determinations. To facilitate the comprehension, further information on the experimental procedures is provided in the following sections, as well as the corresponding results and analysis. 
214 Table 3. The slump of concrete with EAF Slag tends to be smaller than the measured for the reference concrete mixes ( $\mathrm{HC}$ and $\mathrm{HAB})$. This is due to the increase in water absorption and the lack of fines in the EAF slag aggregate. Such problem would have been more evident if the correcting sands had not been used. A higher workability was achieved in mixes with the limestone correcting sand. HS showed an average density $20 \%$ higher than that of $\mathrm{HC}$ and $17 \%$ lower than that of $\mathrm{HAB}$. This is consistent with the difference between the densities of the limestone, barite and EAF slag aggregates (see Table 1). For the density measured the mixes may be classified in three groups: mixes HC with common densities, close to $2400 \mathrm{~kg} / \mathrm{m}^{3}$; concretes with EAF slag aggregates with densities close to $2800 \mathrm{~kg} / \mathrm{m}^{3}$; and $\mathrm{HAB}$ concretes reached a value of $3420 \mathrm{~kg} / \mathrm{m}^{3}$.

Table 2 presents the average values of the compressive strength and the elastic modulus; the standard deviation of the results is not specified since it is within the usual limits (4\% to $8 \%$ as maximum). In relation to the mechanical properties, significant differences are observed between the mixtures tested. On one hand, HS and HC mixes present similar compressive strength values. On the other, HAB exhibit compressive strength values $38 \%$ lower than $\mathrm{HS}$ and $\mathrm{HC}$. This is attributed to the higher fragmentation and exfoliation experienced by the barite aggregate, as described in [47-49]. HSC1b is poorer than HSC1a in terms of mechanical properties despite its water content. To explain the variations observed the air content in fresh state could be used as a quantitative reference parameter, since specimens with more air content are expected to present higher porosity and lower compressive strength. Figure 2 shows the relation between the air content and the compressive strength. As expected, the increase of the former led to a reduction of the latter. In the case of $\mathrm{HAB}$ is observed a behavior completely different than the observed in the other mixtures. Differences in mechanical properties are more evident if the elastic modulus is analyzed, because is mainly influenced by the characteristics of the aggregates (strength, porosity and hardness) than the compressive strength. HS displayed an average elastic modulus $13 \%$ and $66 \%$ higher than those of $\mathrm{HC}$ and $\mathrm{HAB}$, respectively. The difference observed between $\mathrm{HS}$ and $\mathrm{HC}$, is described in [49]; according to the cited literature, despite displaying higher porosity than the conventional limestone, the EAF slags 
242 increment observed in the results. The greater difference observed between HS and HAB results was already described in [49] and it is clearly shown by the SEM images of the next section, being a consequence of the formation of dust around the barite aggregate particle that compromises the contact with the cement paste.

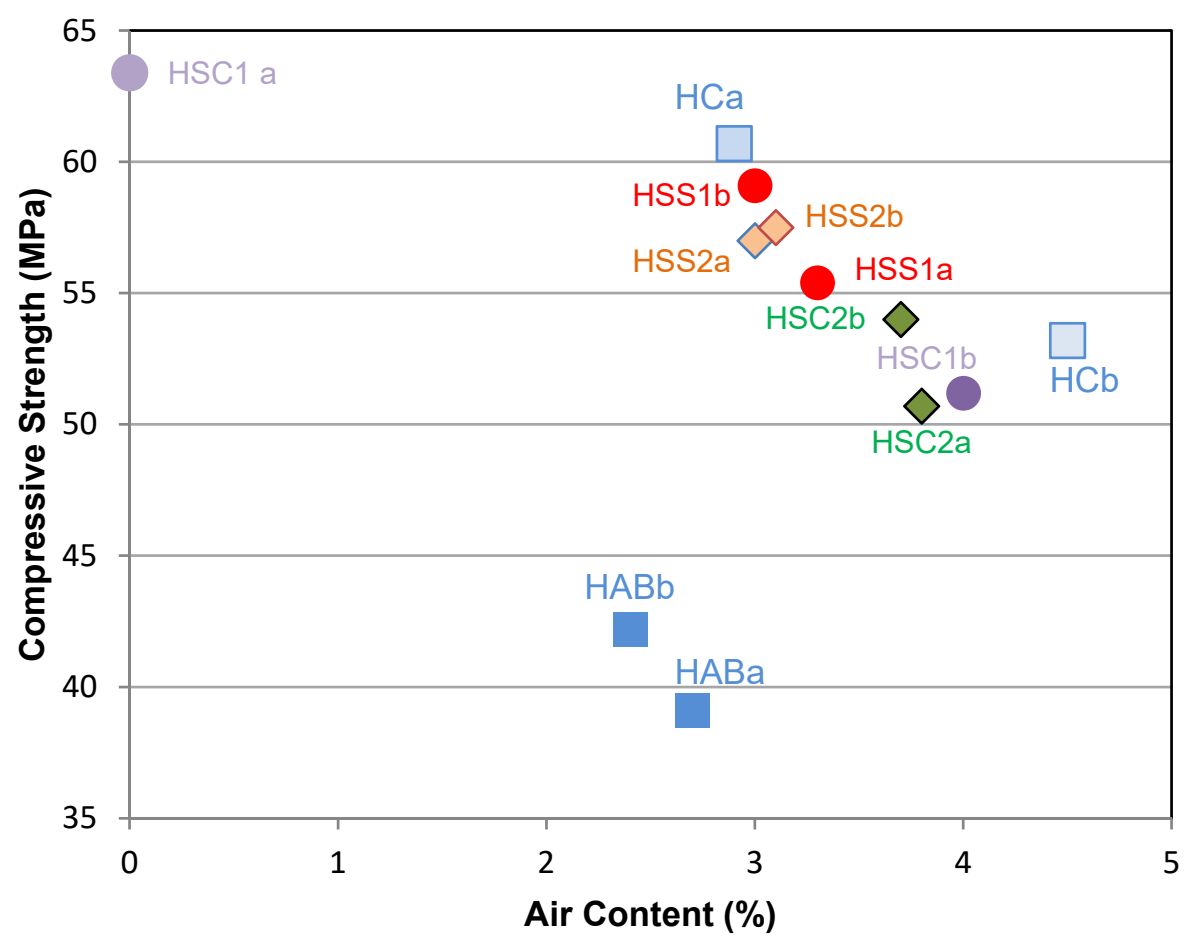

Figure 2: Relation between air content and compressive strength

\section{PHASE II: STABILITY, DURABILITY AND POTENTIAL LEACHING}

\subsection{Depth of water penetration under pressure}

Figure 3 summarizes the maximum and the average depth of water penetration under pressure, as well as the limits established in the Spanish Structural Concrete Instruction [63]. Such depth is considered as an indirect parameter related to the durability. Materials with lower penetration depths are regarded as more durable. 


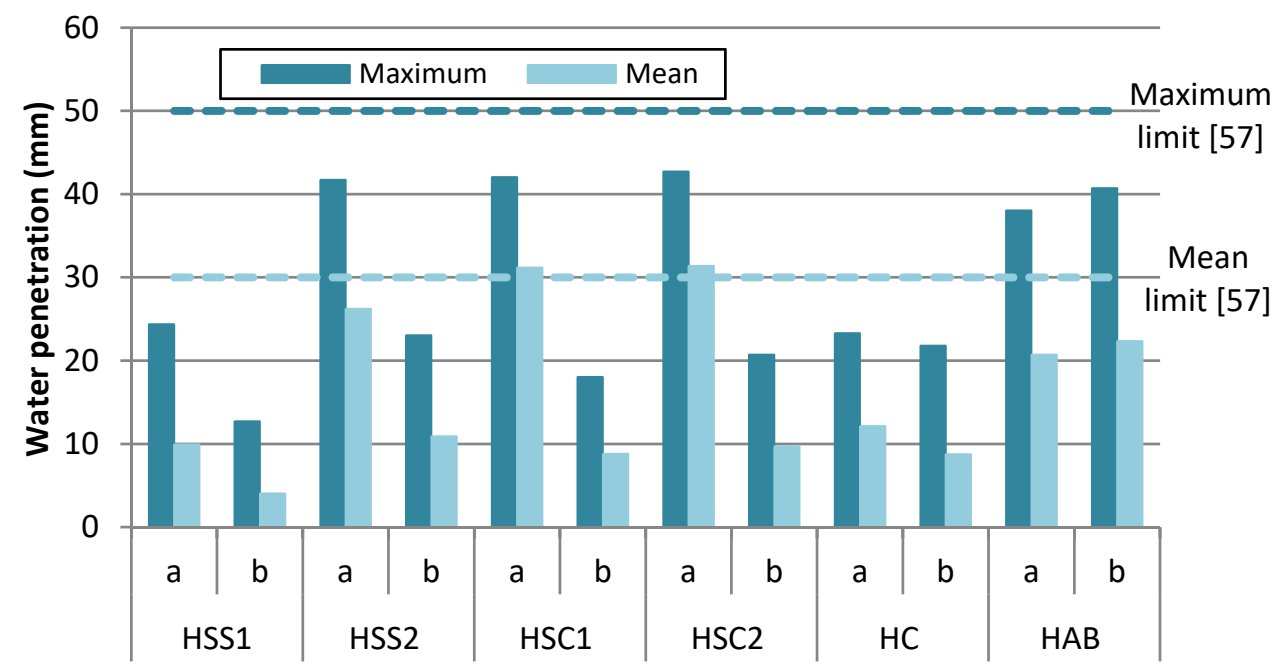

258

259

260

261

262

263

264

265

266

267

268

270

271

272

273

274

275

Type of concrete

Figure 3: Depth of water penetration under pressure

All mixes comply with the limit established in EHE 08 [63], except for HSC1a and HSC2a that present an average penetration depth slightly above the limit. In general, the lower maximum and average values are observed for HC. The higher penetration depths found for HS may be attributed to the higher porosity of the EAF slag used that facilitates the water ingress, being coherent with results obtained by Mercury Intrusion Porosimetry (MIP) in Ortega- López et al [44]. HAB shows penetration depths in the same range as HS. In this case, the low porosity of the barite aggregate does not justify the results, being probably a consequence of the poor quality of the interfacial transition zone between paste and coarse aggregate mentioned in the previous section that facilitates water entrance.

Deeper analysis of Figure 3 reveals that mixes with EAF slag and siliceous correcting sand used display between $2 \%$ and $68 \%$ ( $2 \%-42 \%$ for the maximum values ; $16 \%-68 \%$ for the medium values) lower water penetration than equivalent mixes with limestone correcting sand (HSC), except in the HSS2b mixtures where the maximum and average values of the mixtures are 10 and $11 \%$ higher than in the $\mathrm{HSC} 2 \mathrm{~b}$, respectively. Interestingly, the increase in the proportion of the grading $4 / 10$ in the coarse EAF slag induces an increment in the water penetration under pressure, which is more evident for mixes HSS. Notice that penetration depths for HS mixes with the number 2 (with more 4/10 grading) are consistently higher than for equivalent mixes with the number 1 (with less $4 / 10$ grading). A possible explanation is that in the coarse agregate, the increment in the proportion of the $4 / 10$ grading in relation to $10 / 20$ grading leads to an increase in the number of particles. This decreases the distance 
between adjacent EAF slag particles and increases the total extent of the interfacial transition zone. Both factors could facilitate the penetration of water.

Differences observed between mixes "a" and "b" are significant in all HS, being negligible in HC or in HAC. For the HS, mixes "a" always show penetration depths considerably higher than the measured for equivalent mixes " $b$ ". This trend is observed regardless of the small variation in the $w / c$ of the mixes. For example, mix HSC1b shows lower w/c than $\mathrm{HSC} 1 \mathrm{a}$, whereas $\mathrm{HSC} 2 \mathrm{~b}$ presents higher w/c ratio than HSC2a. However, in both comparisons, the mix "a" shows higher penetration depths than the mix "b". Therefore, the change in w/c does not justify the trend observed.

The main mix modification that could explain this trend is the increase in the admixture content in mixes " $b$ ", where the polyfunctional plasticizer content increased $42 \%$ in relation to the content in mixes "a". Such increase could produce a better cement dispersion and a less permeable microstructure (especially in the interfacial transition zone between paste and EAF slag particle, as shown in SEM image of Figure 4) leading to lower penetration depths. Consequently, a proper definition of the admixture (type and content) seems to be a relevant aspect to enhance the depth of water penetration under water pressure of the concrete with EAF slag.

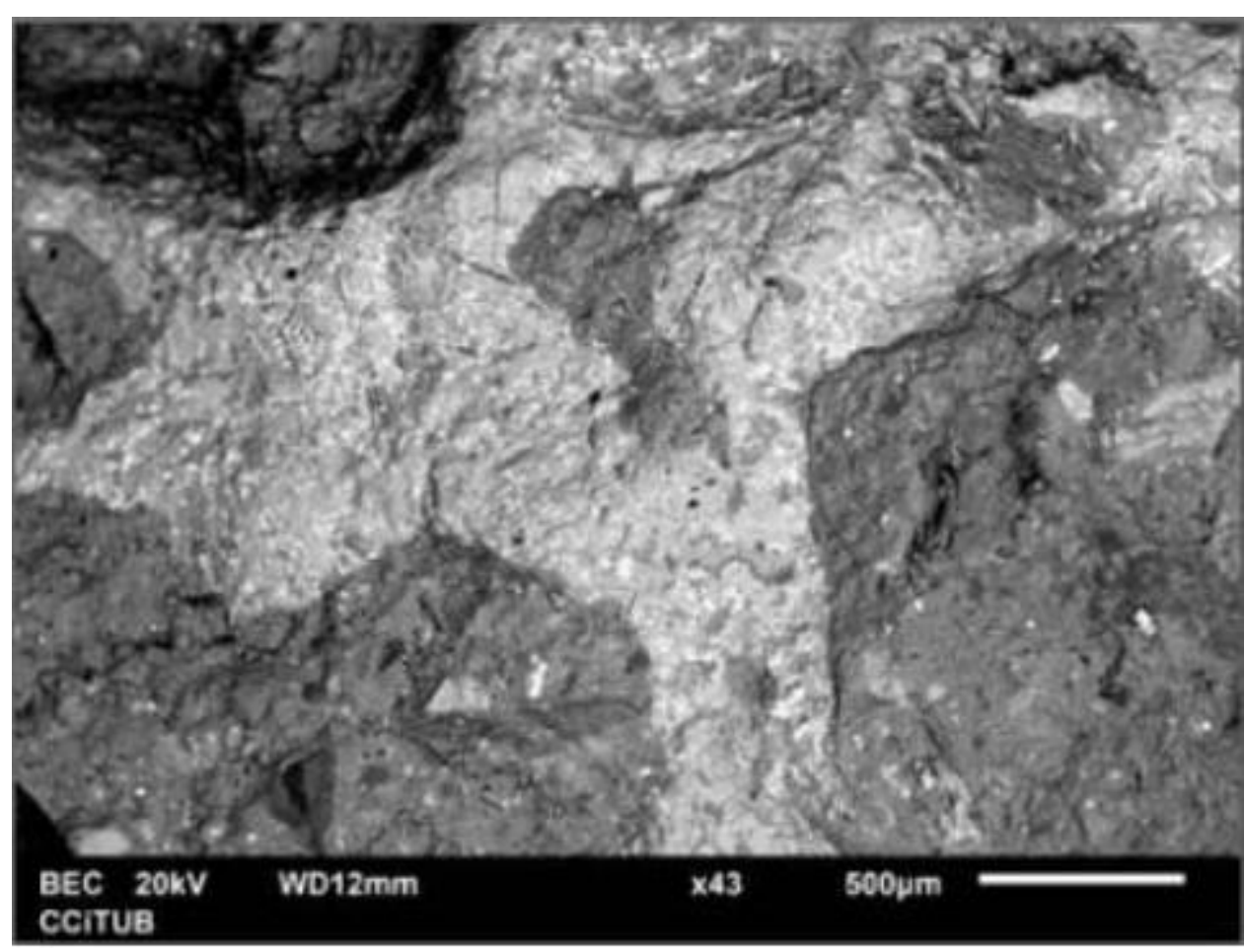




\subsection{Wet-dry cycles}

The alternation between saturated and dry conditions in real structures promotes the oxidation of steel nodules embedded in the aggregates, the hydration of unreacted Calcium and Magnesium Oxide, as well as the mobility of ions from the inside to the surface of the element. The reactions could cause the expansion of the material whereas the mobility of ions could cause stains in the surface of the material with negative aesthetic repercussions. Accelerated wet-dry cycles were performed to evaluate this phenomenon. To reduce the influence of the normal hydration of Portland cement, cycles commenced approximately 4 months after production of the specimens so that most of the hydration of Portland cement would have been completed. The cycles were performed in a climatic chamber at $20^{\circ} \mathrm{C}$. Specimens were fully immerged in water for 24 hours, and then air-dried for 24 hours at 50\% relative humidity. Cubic and slab-shaped specimens were tested in order to evaluate the influence of the surface/volume ratio in the formation of stains on the surface.

At the end of the drying period of each cycle, a visual inspection was conducted to identify any type of wear and the number of stains points on the surface was assessed. Then an evaluation of the dimensional variation was conducted by measuring with a mechanical extensometer the relative distance between four reference points glued to the surface of the slab-shaped specimens. Slabs of mix HSC1b were damaged during transport and could not be assessed.

Visual inspection

Figure 5 shows pictures taken of both types of specimens HSC2a at the end of first cycle and at the end of $44^{\text {th }}$ cycle. Similar results were obtained for other mixes with EAF slag. In all of them, stain points were evident after the first cycle in the form of dark brown spots distributed over the surface. These spots resemble deposition of iron corrosion products that may be identified in the EAF aggregate prior to mixing concrete (figures $5 e$ and $5 f$ ). A significantly larger area covered by stain points is observed after the $44^{\text {th }}$ cycle, thus indicating an additional deposition of iron corrosion products coming from the EAF aggregate. 
a)

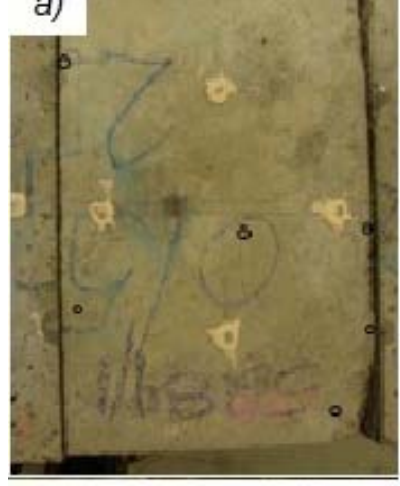

b)

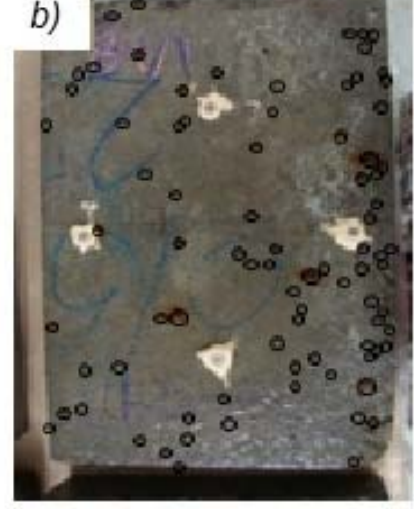

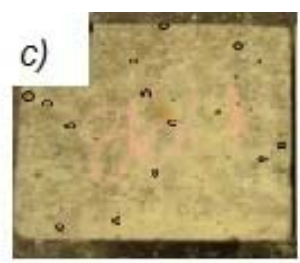

e)

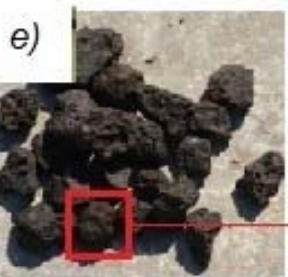

d)
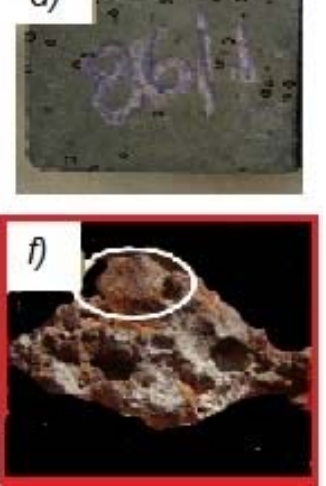

Figure 5: Picture taken at $1^{\text {st }}$ and $44^{\text {th }}$ wet-dry cycle of slab-shaped ( $a$ and b) and cubic (c and d) specimens and iron spot with corrosion embedded in an EAF slag coarse particle (e and f)

This increase over the cycles is more evident in Figure 6 that shows the evolution on the number of stains points on the surface for both specimen shapes. Results for mixes HC and HAC are not presented since they had no visible stains during the test. A faster increase is observed between cycle 1 and 15 . The rate of increase tends to reduce after that, although no clear stabilization is identified after 44 cycles.
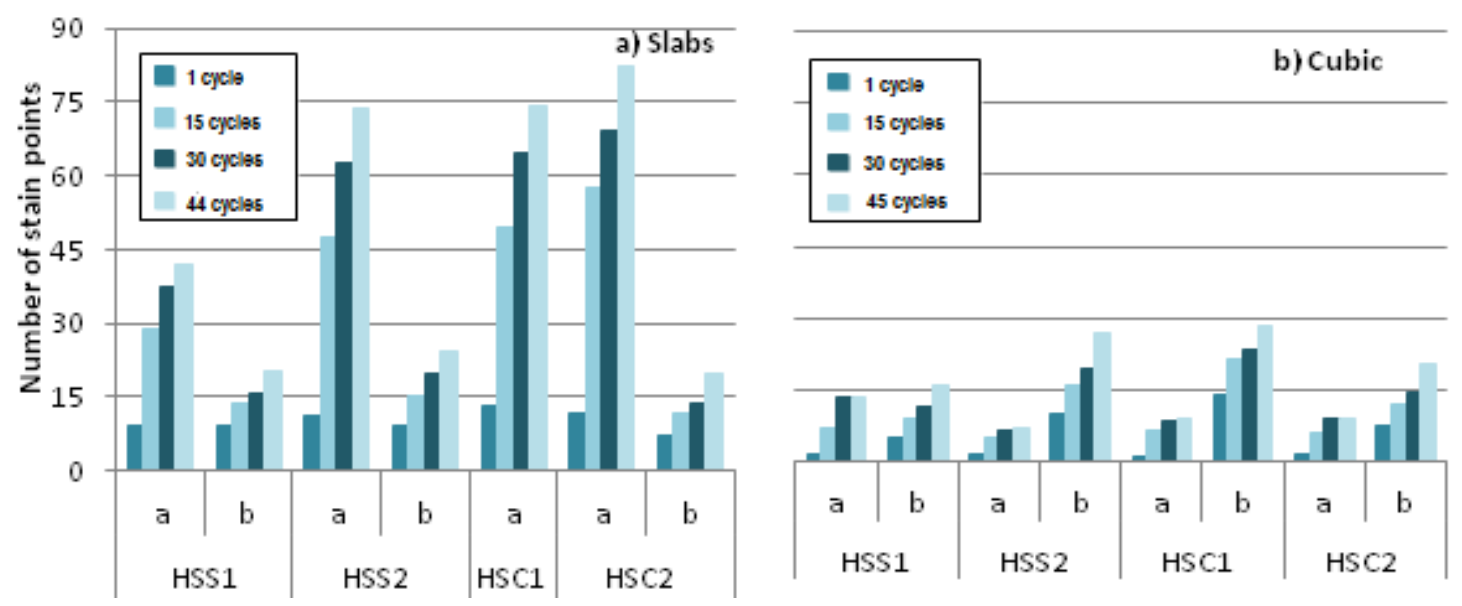

\section{Figure 6: Evolution of number of stains on the surface for slab-shaped (a) and cubic (b) specimens}

For the same cycle, the number of stain points is between 2 and 4 times larger in the slabshaped specimens than in the cubic specimens. Evidently, the formation of these stain points is transport related. The high surface/volume ratio of slab-shaped specimens favors the water interchange with the surrounding, which mobilizes more corrosion products towards the surface. Another factor that 
could contribute to the larger number of stain points in the slab-shaped specimens is the influence of the mold in the position of the aggregate. In the case of slabs, the coarse aggregate (contains the biggest embedded steel spots) tend to align alongside the surface of the mold, being more accessible to the water interchange. The restriction to the position of the aggregates is lower in cubic specimens so that the coarse particles could be farther from the surface, at positions less accessible to water. correcting sand present less stain points than equivalent mixes with limestone correcting sand. The increment in the proportion of the $4 / 10$ grading of the coarse EAF slag also leads to an increment in the number of stain points. This may be related with the presence of a larger number of EAF slag particles closer to the surface as the content of $4 / 10$ grading increases. Consequently, the likelihood that iron accumulations in the aggregate will be mobilized and reach the surface to generate stain points is also enhanced in this case. Furthermore, mixes with higher content of admixture ("b") have 2 to 5 times less stains than equivalent mixes with less admixture ("a"). The permeability of the concrete could limit the access of water and the mobility of corrosion products towards the surface. The general trend observed in Figure $6 a$ is in line with the results of depth of water penetration under pressure from Figure 3 . Notice that the same is not clear in the case of cubic specimens. direct contact with water or to significant variations of humidity. Based on the analysis of the results, proper definition of the proportion of fractions in the coarse EAF slag and of the admixture content may contribute to reduce the number of stain points observed on the surface over time.

Dimensional stability specimens ( $\mathrm{HC}, \mathrm{HAB}$ and $\mathrm{HS}$ ) show negative deformation in the first cycles that indicate a reduction in size. After approximately 15 cycles, the specimens start to present increasing deformations that reach positive values in some of the specimens. In the case of $\mathrm{HC}$ and $\mathrm{HAB}$ the deformation decreases again after 35 cycles, whereas in HS deformations either stabilize or show smaller increments. 
373 Figure 8 . The first phenomenon is the result of the hygro-thermal conditioning. Before the dry-wet test,

374

375 specimens were kept the whole time submerged in water. Therefore, they were saturated when the first cycle was initiated. During the test, however, specimens alternated between saturation and an environment with $50 \%$ relative humidity. Consequently, the average humidity of the specimens tended to reduce in comparison with the prior condition in which they were continuously submerged. The reduction in the humidity takes place until the equilibrium with the average alternated conditions of the test is reached. This is registered as a negative deformation in the form of shrinkage until equilibrium is reached (see Figure 8).
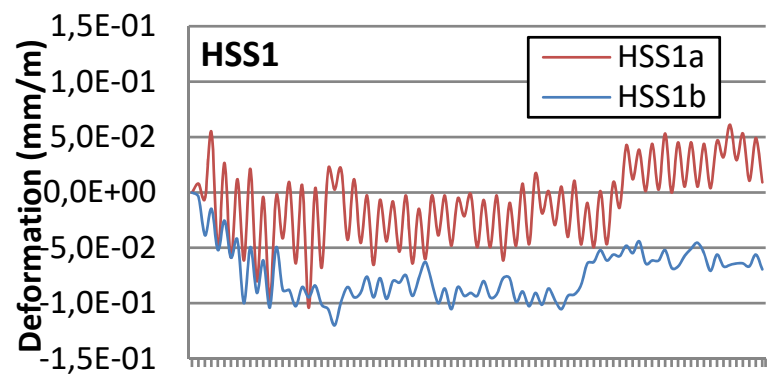

$0 \quad 4 \quad 711141821252832353942$

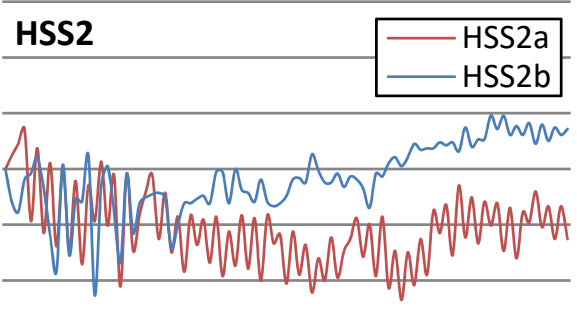

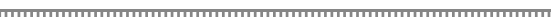
$0 \quad 4 \quad 711141821252832353942$

Number of cycles
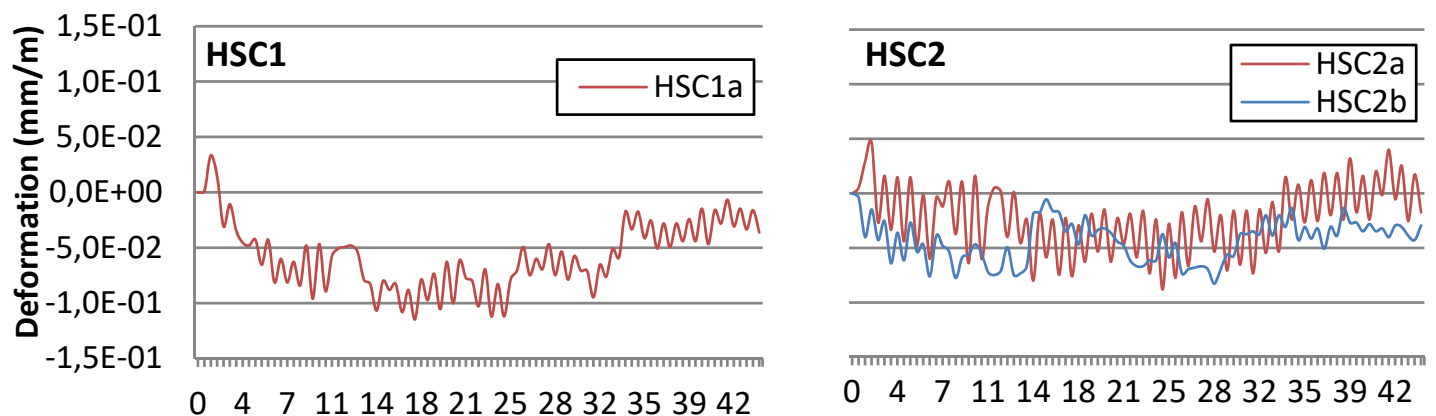

$0 \quad 4 \quad 7 \quad 11141821252832353942$

Number of cycles
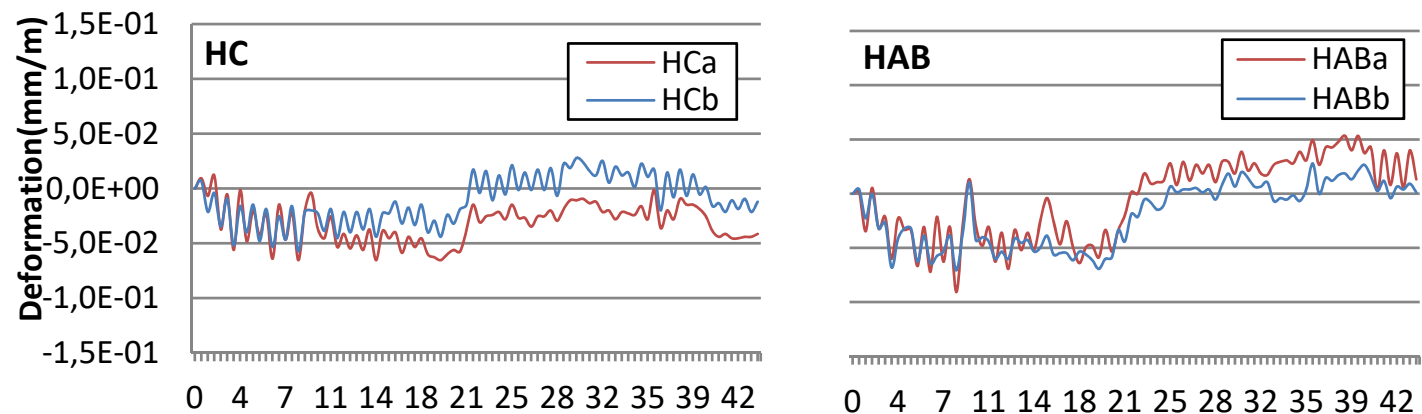

Number of cycles

Figure 7: Deformation of slab-shaped specimens 


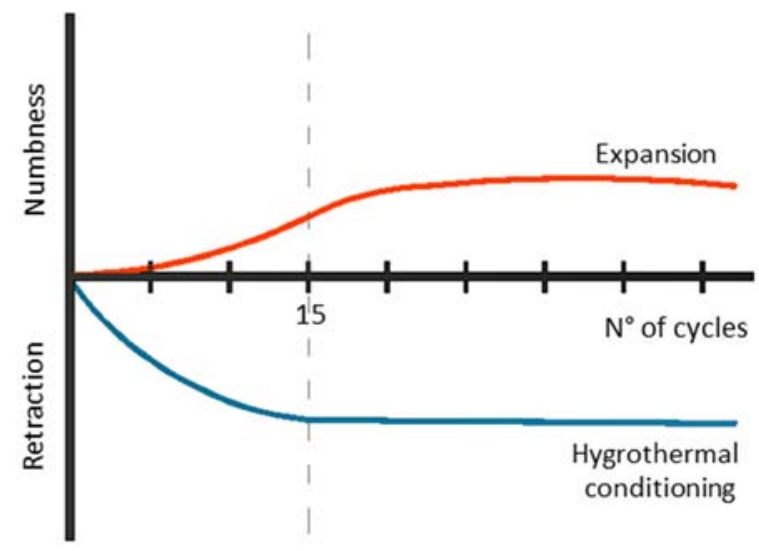

Figure 8: Phenomenon developed during the wet-dry cycles test

The second phenomenon could be related with the expansion produced by the EAF slag since the increase in deformation of HS mixes is observed until the end of the test. Although $\mathrm{HC}$ also shows an increase in deformation after stabilization, the strain values start to decrease again at the end of the test, indicating a return to the stable condition. To have a better idea about the expansion experienced during the test, the total strain variation calculated as the difference between the final deformation (at 44 cycles) and that measured at 15 cycles is presented in Figure 9.

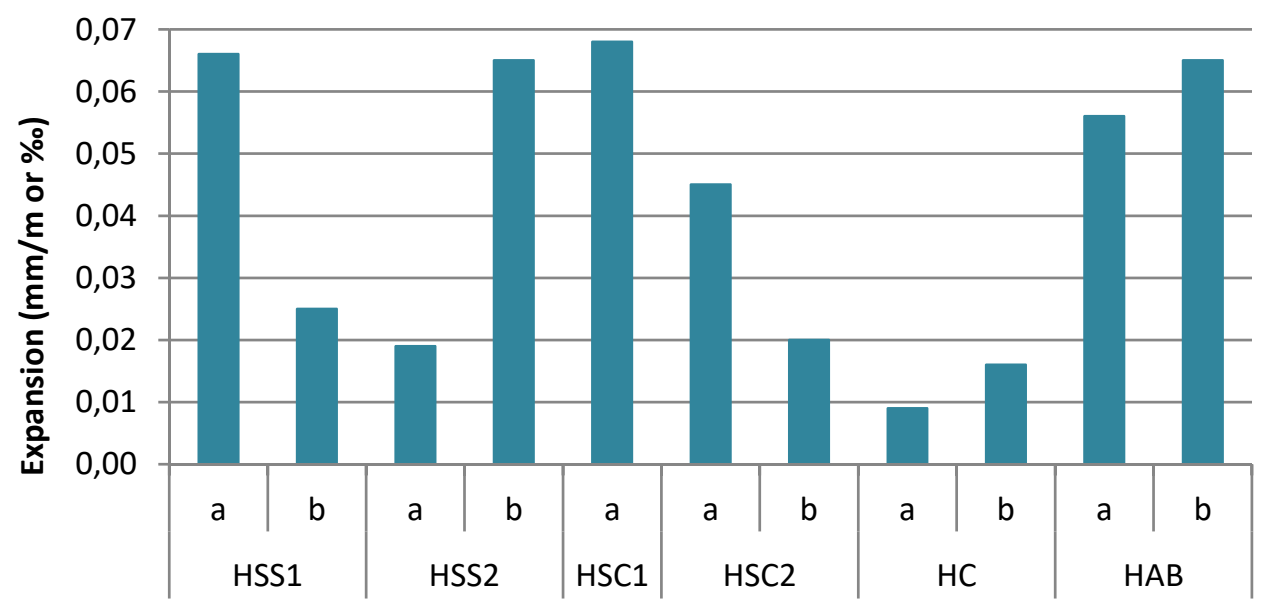

Type of concrete

Figure 9: Expansion meassured between 15 and 44wet-dry cycles

HC shows the smaller expansion with an average of $0.012 \%$, whereas HAB presents an average of $0.060 \%$. On the other hand, HS show expansions ranging from $0.019 \%$ o to $0.068 \%$ o with no clear influence of the type of correcting sand, content of superplasticizer or proportion of coarser fraction in 
405

406

407

408

409

410

411

412

413

414

415

416

417

418

419

420

421

422

423

424

425

426

427

428

429

430

431

432

these results. Despite the higher values of HS in comparison with $\mathrm{HC}$, the structural repercussion of the additional strain is almost negligible.

Studies about other expansive reaction in concrete consider a critical expansion of $1 \mathrm{~mm} / \mathrm{m}[58$, 59] as a maximum to avoid damages and negative structural repercussion. This limit is well above the values measured in the experimental program.

\subsection{Influence of environmental conditions}

Once the wet-dry test was completed, specimens were stored at the climate chamber $\left(20^{\circ} \mathrm{C}\right.$ and relative humidity of $50 \%$ ) for 8 months. After this period, samples were used to evaluate the influence of environment exposure on the deformation. One specimen of each mix was exposed to outdoors conditions at the roof of building C1 at Polytechnic University of Catalonia from February 2013 to February 2014, whilst the remaining specimen was kept in a climate chamber.

The deformation of each element exposed to the outdoor conditions was measured monthly using the same procedure described in section 4.2. After 1 year of exposition, all specimens (including those at the climatic chamber) were cracked through the Brazilian test according to UNE-EN 12390-6: 2010 [66] and the depth of carbonation was assessed according to the UNE-EN 14630: 2007 [67].

\section{Dimensional stability}

Figure 10a shows the daily average temperature and humidity at outdoor conditions during the period of the test. Figure $10 \mathrm{~b}$ presents the deformation measured during the 1-year period.

All mixes show a similar behavior, although $\mathrm{HC}$ has less pronounced oscillations due to the additional influence of the thermal dilatation of solids since the aggregate used is less porous than the EAF slag used in the HS mixes. An initial positive deformation is observed. Again, this is a consequence of the hygro-thermal conditioning of specimens that changed from an environment with constant relative humidity of $50 \%$ to an environment with relative humidity of around $70 \%$ and exposed to rain. The increase in humidity is reflected as a positive deformation in the graph from Figure 10b. 

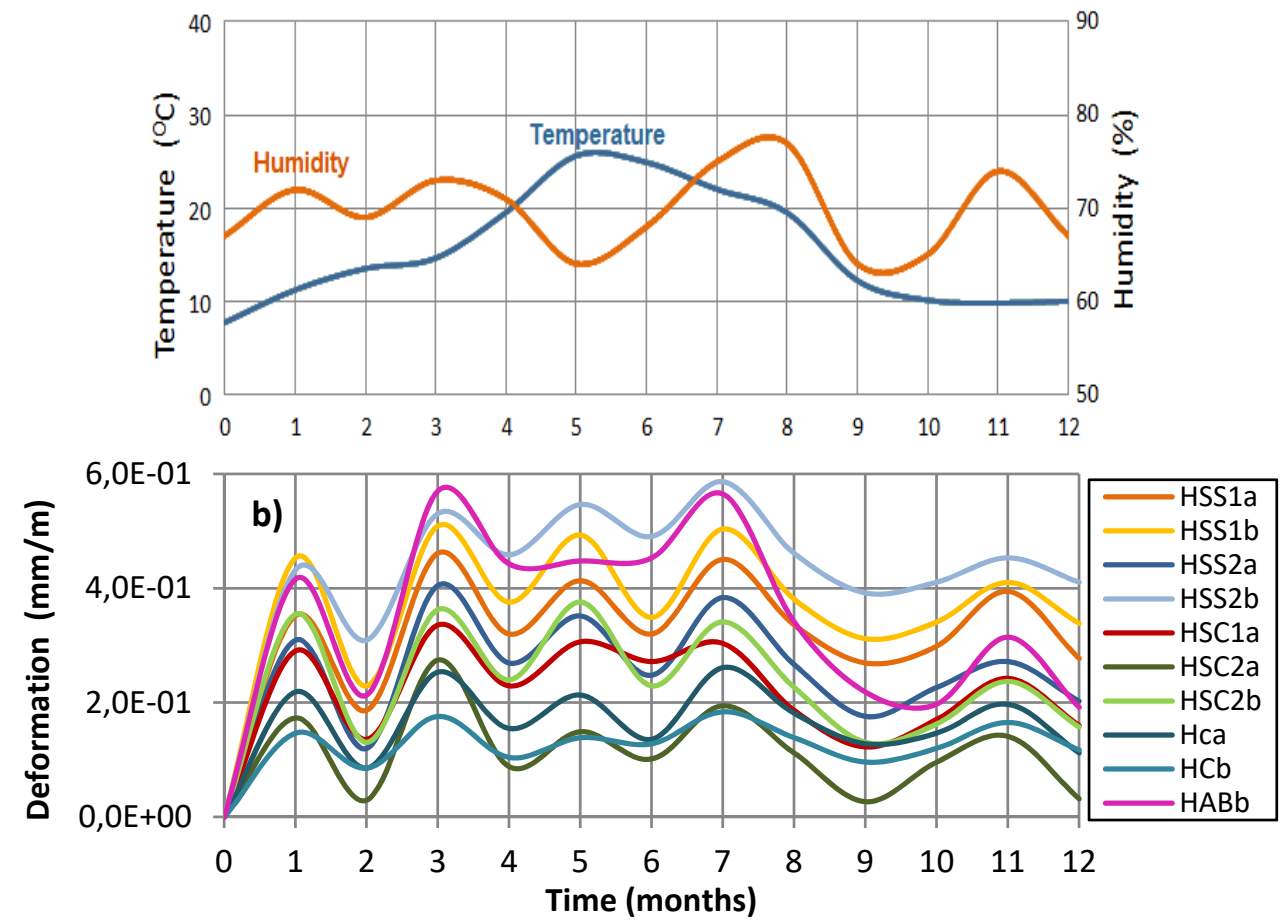

434

Figure 10: a) Temperature and humidity data ; b) deformation for each concrete

\begin{abstract}
Variations observed in the following months were also directly influenced by changes in temperature and humidity of the environment; in terms of the small magnitude orders obtained, additional influence of the thermal dilatation of solids is also relevant. Comparing the deformation at the end of the test with the deformation after the first month (once hygro-thermal equilibrium with the environment should already be reached), all mixes presented practically null dimensional variation. This reveals the stability of the HS mixes
\end{abstract}

\title{
Carbonation
}

Figure 11 depicts the carbonation depth for specimens located outdoors and in the climatic chamber. The lowest depth values were measured for HAB and HC, both below $1 \mathrm{~mm}$. Conversely, HS presented a carbonation depth from 1 to 6 times higher than $\mathrm{HC}$ and $\mathrm{HAB}$. This increase is consistent with the results of depth of water penetration under pressure presented in 4.1. The lower water penetration depths found for HS explain their higher carbonatation depth, considering the fact that the carbon dioxide can act as gas and dissolved in water. 


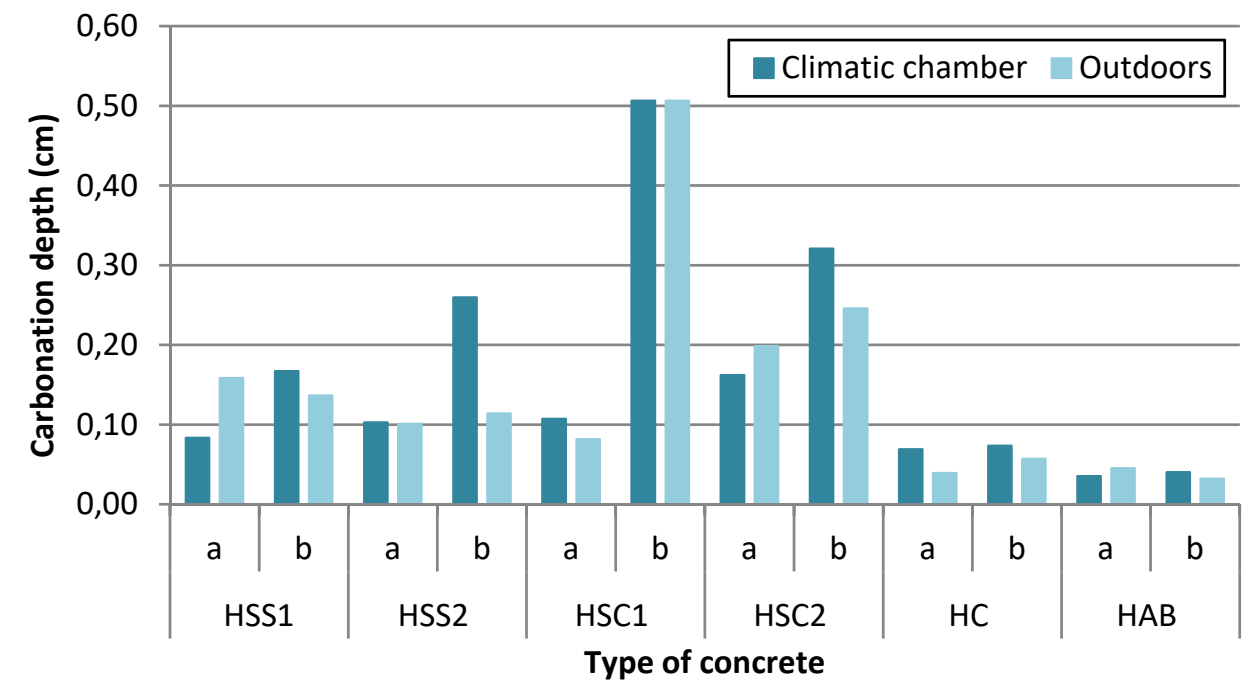

452

453

454

455

456

457

458

459

460

461

462

463

464

465

466

467

468

469

470

471

472

Figure 11: Carbonation depth

No clear influence of the proportion of coarse fraction of EAF slag was observed. In general, mixes with higher content of superplasticizer ("b") showed $44 \%$ higher carbonation depths than equivalent mixes with less content of superplasticizer ("a"). Likewise, mixes with limestone correcting sand present higher average carbonation depths than equivalent mixes with siliceous correcting sand. These findings are consistent with the results of depth of water penetration under pressure.

Specimens kept in the climatic chamber tend to have similar carbonation depths (in average) than those exposed to outdoor conditions, except in the HSS2b mix that shows an anomalous behavior. The higher humidity and the rain exposure reduces the average $\mathrm{CO}_{2}$ diffusion coefficient and, hence, the penetration depth.

\subsection{Freeze - thaw cycles}

An issue of great relevance in concrete pavements is the long-term behavior when subjected to freeze-thaw cycles. These cycles produce two main degradation processes: cracking and scaling of concrete surface. The resistance of concrete against freeze-thaw cycles is linked to the porosity and pore spacing of the material. In that sense, the greater porosity of EAF slag used in this work could be beneficial if it generates chambers to cushion the pressure increase caused by the freezing water. On the contrary, the material could also have a negative effect in case it favors accumulation of water in the surface layers, increasing the internal stresses generated. 
474 described in the technical literature. The procedure adopted here is based on the defined by Manso [32] and Pellegrino [27]. To carry out the freeze-thaw cycles, all the test specimens were subjected to the same initial conditions. After demolded, these were cured two years in a humid chamber (with standard temperature and humidity, $\mathrm{T}=20^{\circ} \mathrm{C}$ and $\mathrm{RH}>95 \%$, respectively), after they were totally immersed in a water container at room temperature for 24 hours ( in order to reach the saturation state); after 24 hours, with the saturated test specimens, the freeze-thaw cycles were started. In each cycle, specimens were kept during 18 hours inside a freezer at $-15^{\circ} \mathrm{C}$. Then, they were immersed for 6 hours in containers with water at $20^{\circ} \mathrm{C}$. In total, 68 cycles were applied. Specimens were visually inspected to detect cracking or surface scaling in every cycle. Measurements of ultrasonic pulse velocity according to UNE-EN 12504-4: 2006 [68] were performed at cycles $1,12,25,40,60$ and 68 to detect microcracking. At the beginning of the test and after 68 cycles, a microstructural evaluation was conducted by scanning electron microscopy and the compressive strength was assessed according to 12390-3 UNE-EN: 2009 [59].

Visual inspection

During the test, no sign of degradation was observed in HC and HS. Instead, HABb showed deterioration and cracks. The first visible crack appeared after 50 cycles at the base of the specimen
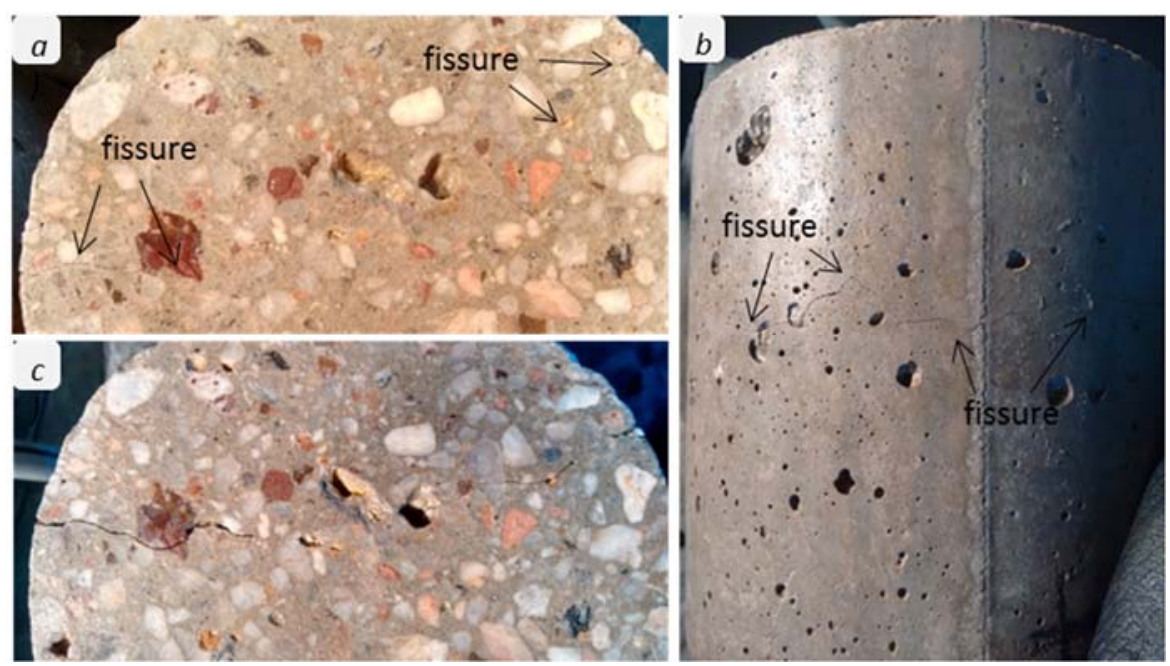
submerged condition was accompanied by a cracking sound similar to the observed when ice cubes are new cracks and to the increase of existing ones.

502

\section{$\underline{\text { Ultrasonic pulse velocity }}$}

504

Figure 13 presents the ultrasonic pulse velocity at the beginning of the test and after 68 cycles, as well as the relative variation experienced. At the beginning of the test similar velocities are assessed for $\mathrm{HC}$ and $\mathrm{HS}$, with average values of 5.06 and $5.21 \mathrm{~m} / \mathrm{s}$, respectively. In contrast, $\mathrm{HAB}$ showed $30 \%$ lower pulse velocity possibly as a result of the poor paste-aggregate connection in the interfacial transition zone as shown by the SEM images of the further sections, in the microstructural evaluation.
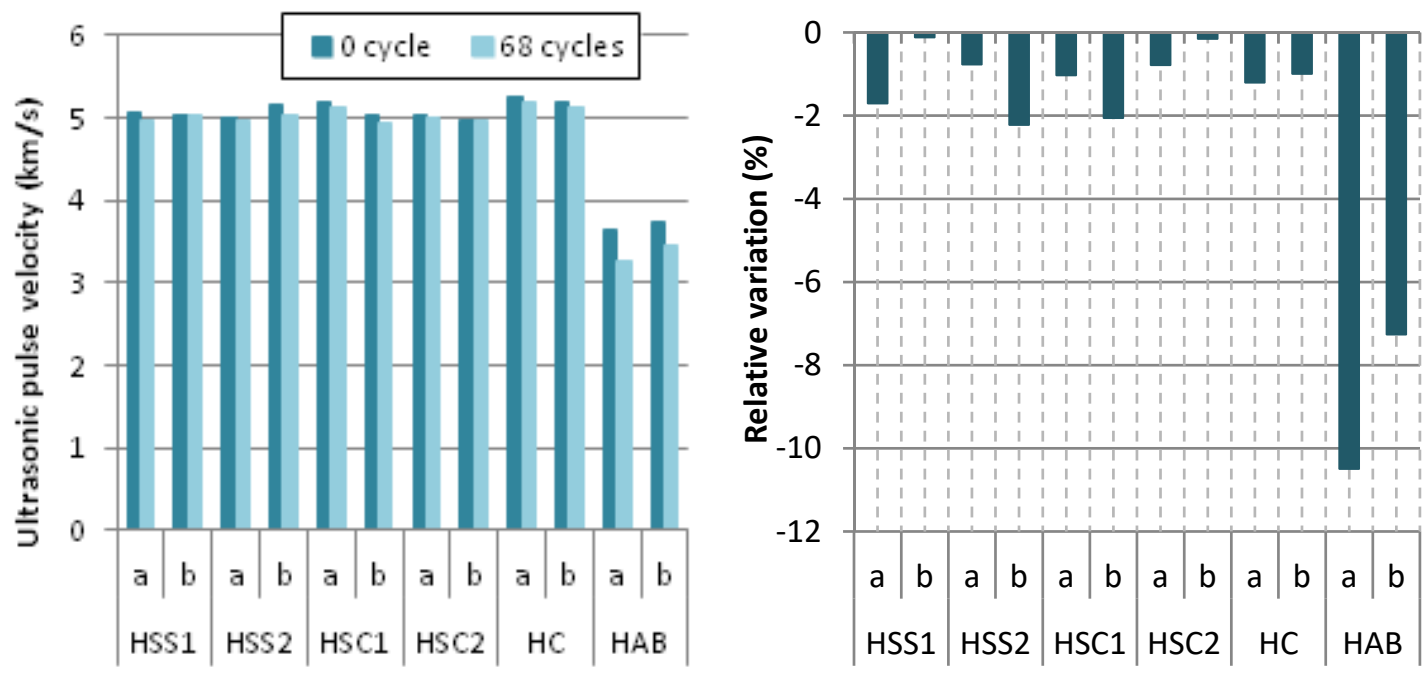

Figure 13: Ultrasonic pulse velocity (a) Realtive variation (b)

A reduction of the ultrasonic pulse velocity was observed in all mixes after the final cycle. In 

5 times larger was observed in the case of $\mathrm{HAB}$, with an average of $8.8 \%$. This is consistent with the result of the visual inspection, suggesting a more pronounced formation of cracks.

\section{Compressive strength} the relative variations.
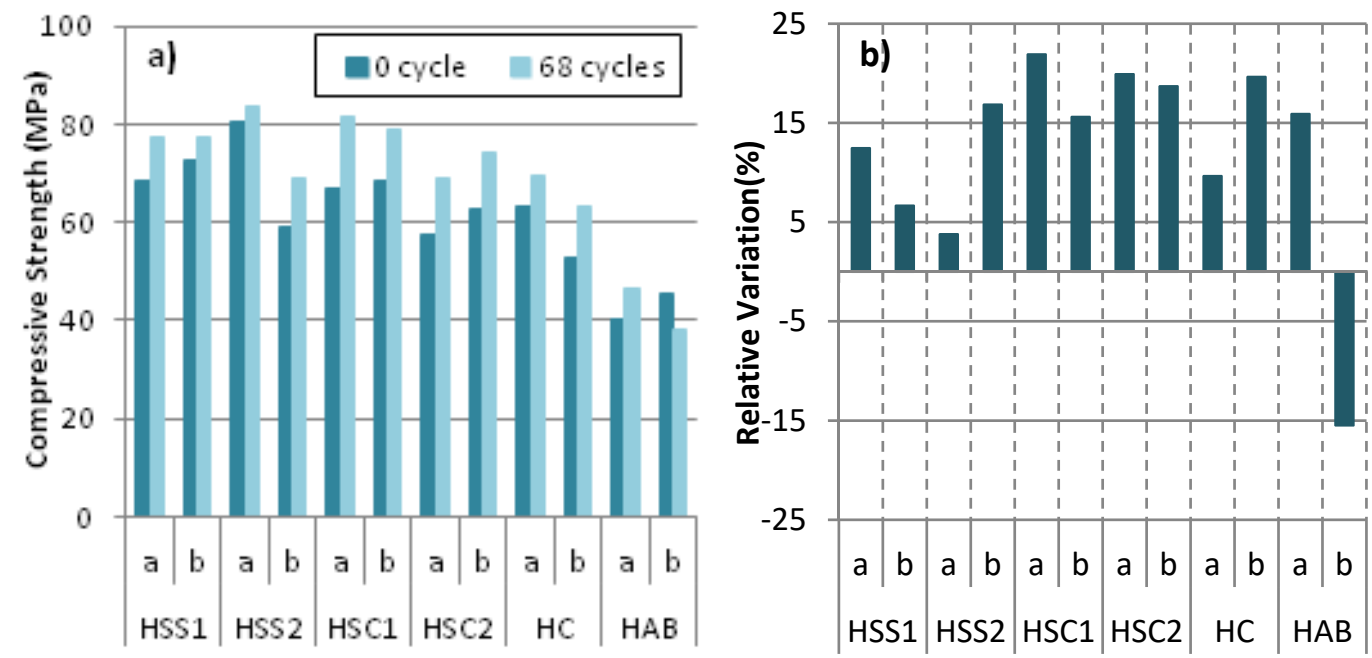

Figure 14: Compressive strength at 0 and 68 cycles (a) and relative variation (b)

Except for $\mathrm{HABa}$, all other mixes presented an increment in the compressive strength after the final freeze-thaw cycle. In fact, HS with siliceous correcting sand showed a $9 \%$ increment, whereas HS with limestone correcting sand showed a $19 \%$ increment. These results are similar to those by Arribas et al. [40] that found increments of $19 \%$ and $7 \%$ after 300 freeze-thaw cycles.

\section{$\underline{\text { Microstructural evaluation }}$}

Figure 15 shows the SEM images obtained in a sample extracted from a HC specimen before and after the freeze-thaw test. An intimate contact between the aggregate and the cement paste in the interfacial transition zone is maintained after the cycles. Moreover, no microcracks were generated by the expansion of water, suggesting that the concrete remains in good condition after the test. 

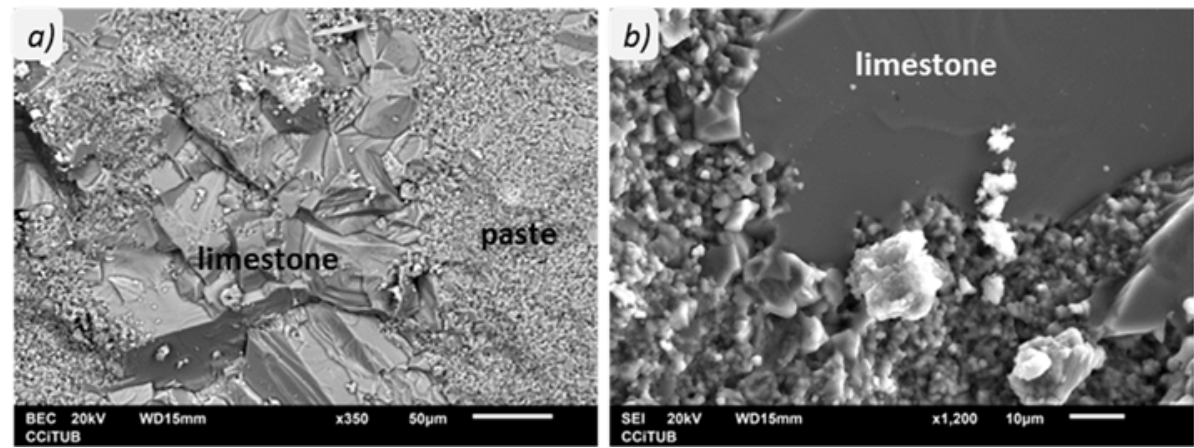

Figure 15: HC sample before (a) and after (b) freeze-thaw cycles
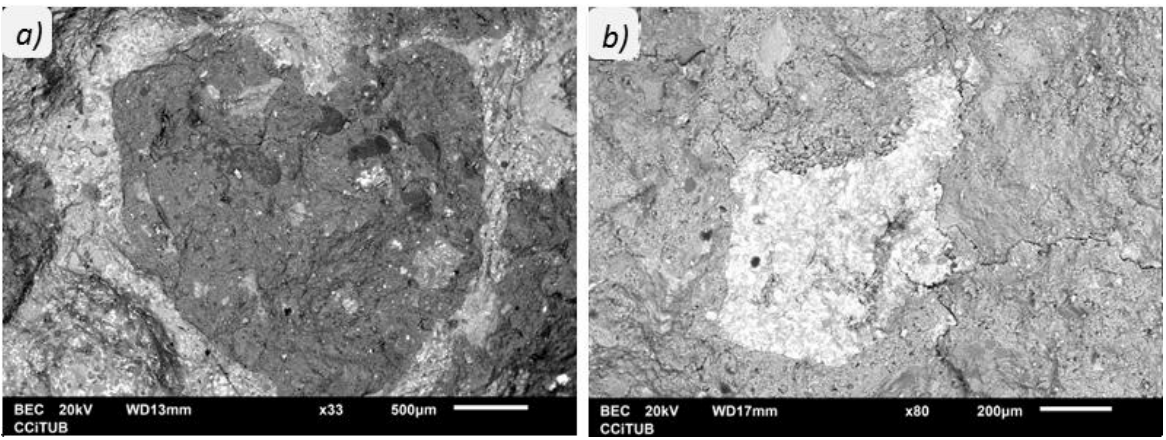

Figure 16: HS sample before (a) and after (b) freeze-thaw cycles

Figure 16a corresponds to a sample extracted from a HS specimen before the freeze-thaw

cycles. The EAF slag particles are fully enclosed by the cement paste, which indicates an intimate contact and good quality of interfacial transition zone. The same conclusion is derived from the analysis of Figure 16 taken from a sample after completing the test. The freeze-thaw cycles do not seem to have affected the interfacial transition zone. Furthermore, although some microcracks are observed that are due to the procedure of obtaining the sample, no microcracks are identified in the matrix related to such cycles nor any compound that would indicate degradation is observed. All these conclusions corroborate the good condition of all HS mixes subjected to freeze-thaw cycles.

Figure 17a and 17b show the SEM images of samples extracted from the HAB before the freeze-

554 thaw cycles. A gap of up to $1 \mu \mathrm{m}$ between the barite aggregate particles and the cement paste is 555 identified, reflecting a poor connection and an interfacial transition zone of deficient quality. This could be the result of the wear phenomenon described in [47] caused by the fragmentation of the barite

557 aggregate. The dust generated accumulates over the particle, thus compromising the formation of the interfacial transition zone. An increase in the paste porosity around the particles is also observed (Figure 
560 the low compressive strength observed before the beginning of the freeze-thaw cycles of HAB.

561

562

563

564

565

566

567

568

569

570

571

572

573
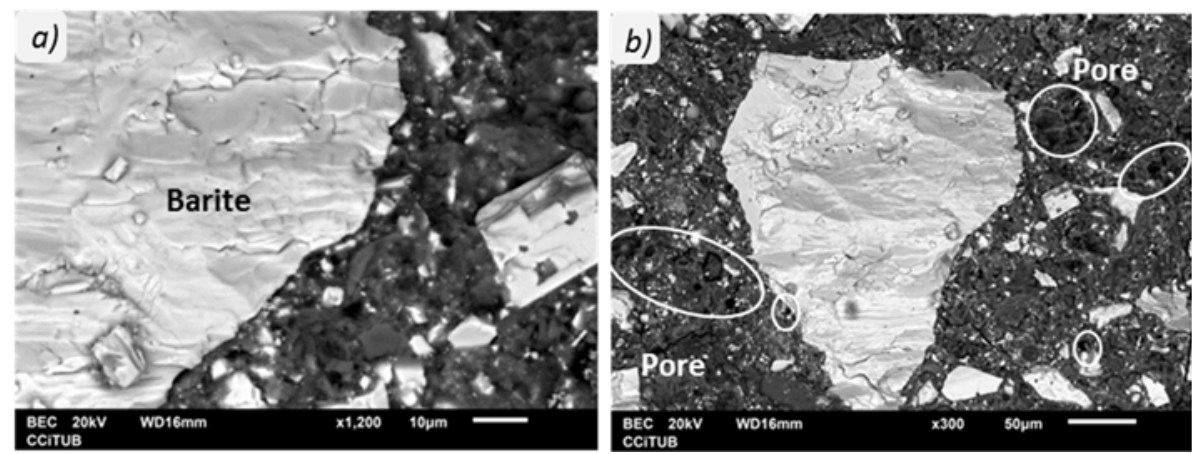

Figure 17: $H A B$ before freeze-thaw cycles: poor connection between aggregate and paste (a) and porosity of paste around the aggregate (b)

Figure 18 presents SEM images of samples extracted from HAB after completion of the freezethaw test. An increase in the gap between the barite aggregate particle and the surrounding cement paste is observed, reaching $4 \mu \mathrm{m}$ at various points. Cracks are also observed in the cement paste. Both evidences are a consequence of the damage induced by the freeze-thaw cycles. The original gap identified before the test favors the entrance and the accumulation of water. As it freezes, water generates pressure that enlarges the gap and produce the cracks. This compromises the compressive strength and the durability of $\mathrm{HAB}$ against freeze-thaw cycles. 

presence.
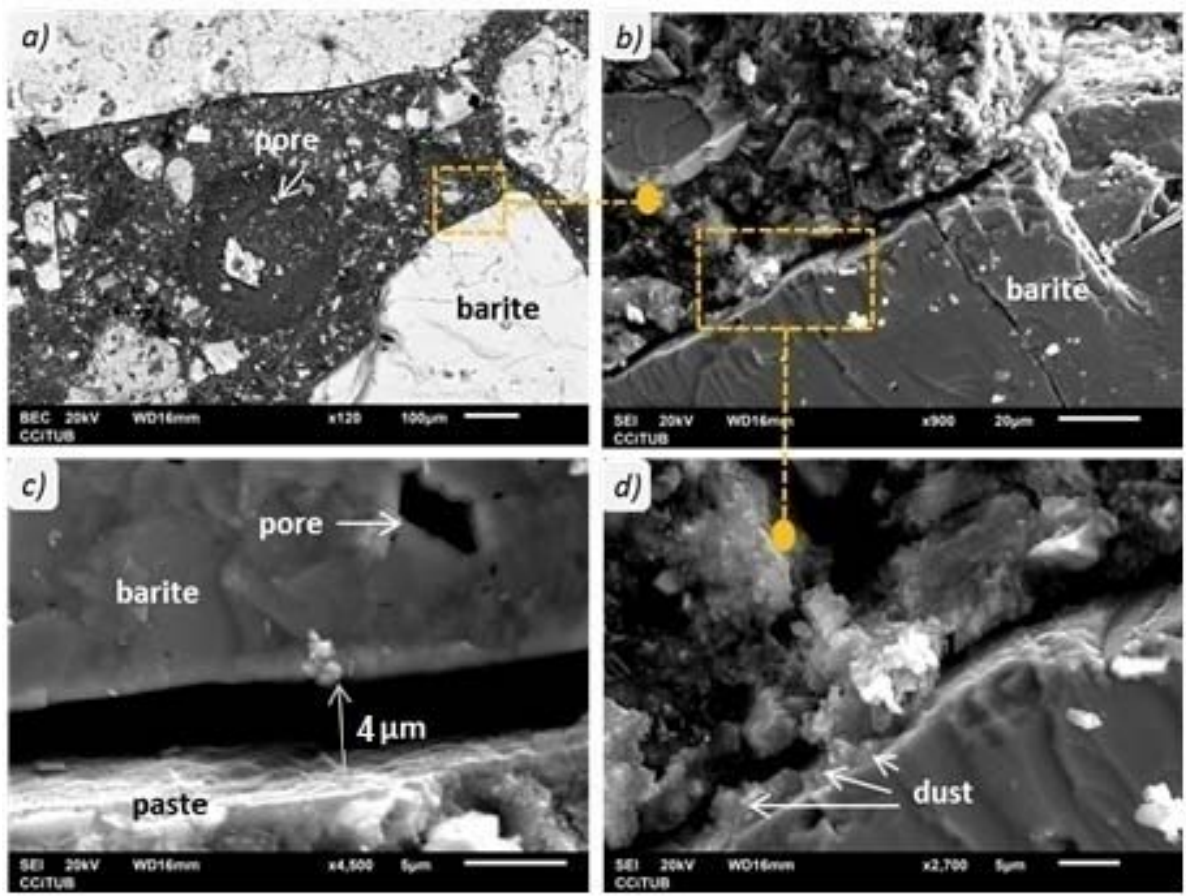

Figure 18: HAB after freeze-thaw cycles: general view ( $a, b$ and $d$ ) and detail of space between barite aggregate and cement paste (c)

\subsection{Leaching}

Leaching tests were intended to determine whether any soluble element could be transported from the HS to the environment, reaching unacceptable concentrations. The test was conducted only for samples HSS1b (with siliceous correcting sand), HSC1a (with limestone correcting sand) and, for comparative purposes, $\mathrm{HCa}$.

Deionized water was used as leaching agent. Sampling and renewal were conducted at 6 hours, 1 day, 2, 4, 9, 16 and 36 days. In each extraction, three samples were taken. One of them was acidified with nitric acid to a $\mathrm{pH}$ of 2 for the determination by ICP of the contents of $\mathrm{Ba}, \mathrm{Cd}, \mathrm{Cr}, \mathrm{Cu}, \mathrm{Ni}, \mathrm{Pb}, \mathrm{Zn}, \mathrm{Se}$, $\mathrm{V}, \mathrm{Fe}, \mathrm{Ca}, \mathrm{Al}, \mathrm{Na}, \mathrm{Mg}$ and $\mathrm{Mn}$. The other two samples were used to measure $\mathrm{pH}$ and conductivity. Later they were acidified to determine the contents of $\mathrm{SO}_{4}^{-2}$ and $\mathrm{F}^{-}$through ion chromatography.

Figure 19 shows the average $\mathrm{pH}$ and conductivity measured. Notice that both parameters increase over time. Nevertheless, HS show lower increments than reference limestone concrete (HC). The low conductivity of HS may be attributed to the low content of soluble salts and a scarce ionic 
593

594

595

596

597

598

599

600

601
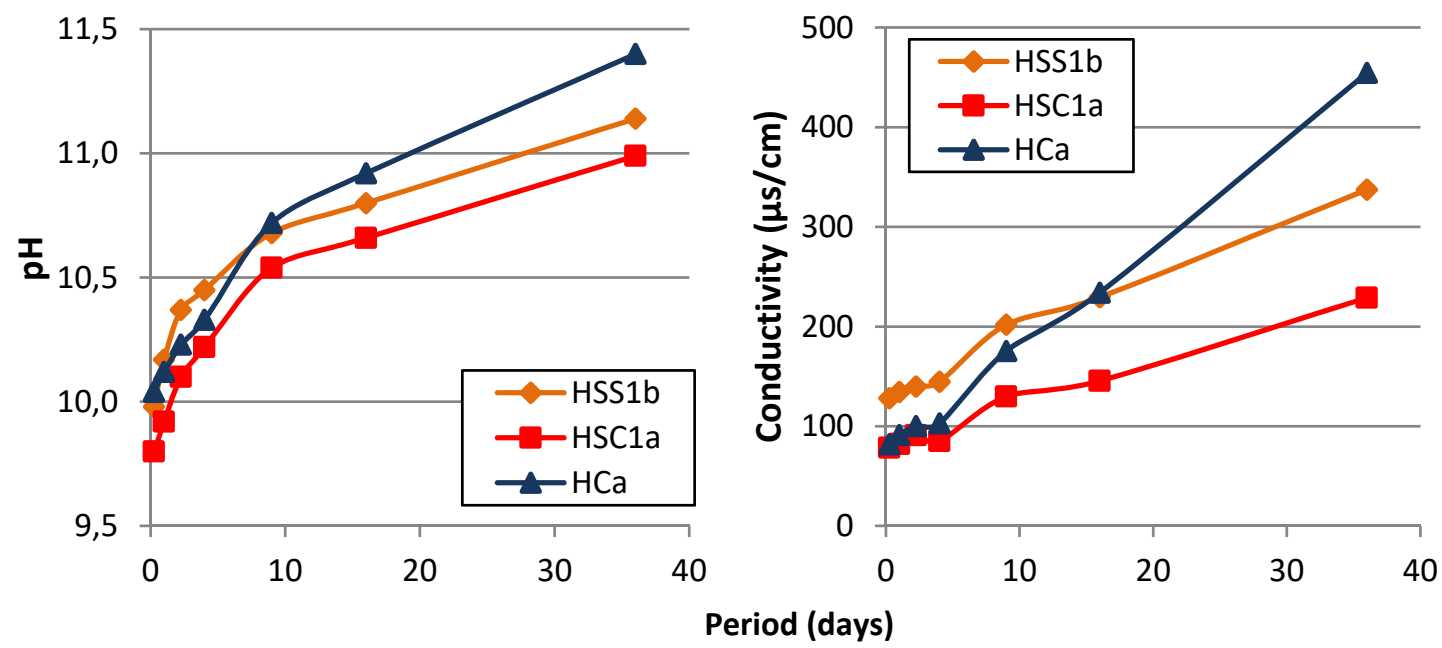

Figure 19: Values for each type of concrete: a) $\mathrm{pH}$ yb) conductivity

Table 4 shows the average concentration values of each component leached at 6 hours, 4 and

36 days. The concentration of the majority of contaminants $(\mathrm{Ba}, \mathrm{Cd}, \mathrm{Cr}, \mathrm{Cu}, \mathrm{Pb}, \mathrm{Zn}$, and $\mathrm{V})$ is close to 0 in all samples. Likewise, $\mathrm{Ni}$ and $\mathrm{Se}$ are below detection limits. The concentration of $\mathrm{Ba}, \mathrm{SO}_{4}^{-2}$ and $\mathrm{F}^{-}$are less than the boundaries defined in Dutch law $\left(600,1500\right.$ and $25000 \mathrm{mg} / \mathrm{m}^{2}$, respectively) [56].

\begin{tabular}{|c|c|c|c|c|c|c|c|c|c|}
\hline \multirow{2}{*}{ Component } & \multicolumn{3}{|c|}{ HSS1b } & \multicolumn{3}{|c|}{ HSC1a } & \multicolumn{3}{|c|}{$\mathrm{HCa}$} \\
\hline & $6 \mathrm{~h}$. & $4 \mathrm{~d}$. & $36 \mathrm{~d}$. & $6 \mathrm{~h}$. & $4 \mathrm{~d}$. & $36 \mathrm{~d}$. & $6 \mathrm{~h}$. & $4 \mathrm{~d}$. & $36 \mathrm{~d}$. \\
\hline $\mathrm{Ba}$ & 0.0002 & 0.0002 & 0.0001 & 0.0006 & 0.0002 & 0.0002 & 0.0003 & 0.0001 & 0.0001 \\
\hline $\mathrm{Cd}$ & 0.0000 & 0.0000 & 0.0000 & 0.0000 & 0.0000 & 0.0000 & 0.0000 & 0.0000 & 0.0000 \\
\hline $\mathrm{Cu}$ & 0.0001 & 0.0000 & 0.0000 & 0.0000 & 0.0000 & 0.0000 & 0.0000 & 0.0000 & 0.0000 \\
\hline $\mathrm{Cr}$ & 0.0000 & 0.0000 & 0.0000 & 0.0000 & 0.0000 & 0.0000 & 0.0000 & 0.0000 & 0.0000 \\
\hline $\mathrm{Ni}$ & n.d. & n.d. & n.d. & n.d. & n.d. & n.d. & n.d. & n.d. & n.d. \\
\hline $\mathrm{Pb}$ & 0.0000 & 0.0000 & 0.0000 & 0.0000 & 0.0000 & 0.0000 & 0.0000 & 0.0000 & 0.0000 \\
\hline $\mathrm{Zn}$ & 0.0000 & 0.0000 & 0.0000 & 0.0001 & 0.0000 & 0.0000 & 0.0000 & 0.0000 & 0.0000 \\
\hline $\mathrm{Se}$ & n.d. & n.d. & n.d. & n.d. & n.d. & n.d. & n.d. & n.d. & n.d. \\
\hline $\mathrm{V}$ & 0.0000 & 0.0000 & 0.0001 & 0.0000 & 0.0000 & 0.0000 & 0.0000 & 0.0000 & 0.0000 \\
\hline $\mathrm{Fe}$ & 0.0001 & 0.0001 & 0.0001 & 0.0003 & 0.0001 & 0.0000 & 0.0001 & 0.0001 & 0.0001 \\
\hline $\mathrm{Ca}$ & 0.0041 & 0.0079 & 0.0178 & 0.0054 & 0.0138 & 0.0463 & 0.0053 & 0.0110 & 0.0945 \\
\hline $\mathrm{Al}$ & 0.0005 & 0.0008 & 0.0032 & 0.0005 & 0.0006 & 0.0020 & 0.0005 & 0.0005 & 0.0033 \\
\hline $\mathrm{Mg}$ & 0.0003 & 0.0003 & 0.0001 & 0.0004 & 0.0007 & 0.0003 & 0.0003 & 0.0003 & 0.0001 \\
\hline $\mathrm{Mn}$ & 0.0000 & 0.0000 & 0.0000 & 0.0000 & 0.0000 & 0.0000 & 0.0000 & 0.0000 & 0.0000 \\
\hline $\mathrm{F}$ & -- & -- & 0.0002 & -- & -- & 0.0001 & -- & -- & 0.0001 \\
\hline $\mathrm{SO}_{4}$ & -- & -- & 0.0013 & -- & -- & 0.0007 & -- & -- & 0.0010 \\
\hline
\end{tabular}



with limestone correcting sand presents higher Ca concentration than the HS with siliceous correcting sand. Results indicate that HS is not a dangerous source of contaminants to the environment, behaving like the reference concrete.

610

\section{CONCLUSIONS}

613

The evidences provided in this study indicate that, if adequately treated, EAF slag may be used as an aggregate for the production of concrete in applications with low structural responsability. In fact, the durability, the long-term stability and the contamination potentially assessed for the concrete with the EAF slag used in this work comply with the requirements of typical structural concretes. The most relevant conclusions based on the results of the experimental program conducted here are described below.

- HS tends to present greater depth of water penetration under pressure than equivalent HC. This is the consequence of the high porosity of EAF slag used that facilitates water ingress. On the contrary, similar results are obtained for $\mathrm{HS}$ and $\mathrm{HAB}$ due to the poor interfacial transition zone around the barite aggregates that also facilitate the water penetration. Even though, practically all mixes comply with the maximum and average penetration values established in [57], special attention should be payed to those with EAF slag since they tend to be closer to the limit.

- The water interchange with the surrounding simulated through the wet-dry cycles reveals that water mobilizes the products from corroded iron nodules present in the EAF slag particles, transporting and depositing them on the surface of HS specimens. Consequently, an increasing number of stain points is observed over the wet-dry cycles whereas no alteration occurs in reference specimens ( $\mathrm{HC}$ and $\mathrm{HAB}$ ). This should be taken into account in elements with high aesthetic requirement, subjected to rainfall or significant variations of humidity. 
- The evaluation of the dimensional stability under dry-wet cycle or under outdoor environmental conditions indicates that the expansive potential of HS may be slightly higher than that of reference $\mathrm{HC}$.

- HS tends to present a carbonation depth between 1 and 6 times higher than $\mathrm{HC}$ and HAB. The faster increase of the carbonation depth should be taken into account when considering the corrosion of structural elements made with $\mathrm{HS}$ and reinforced with steel bars.

- The durability of the HS against freeze-thaw cycles was similar to that of HC. No sign of cracks or scaling were observed in HS and HC. Conversely, HAB presented 5 times higher reduction in the ultrasound pulse velocity, indicating the presence of microcracks. Visible cracks with negative repercussion in the compressive strength were also observed after 40 freeze-thaw cycles.

- The HS, with the EAF used in this study, comply with the contaminant release limits to the environment established in the literature.

\section{ACKNOWLEDGEMENTS}

The authors thank the technical support, resources and facilities provided by the company Promotora Mediterranean S.A. (PROMSA) under the collaboration project entitled "Study of the behavior of concrete made with electric arc steel slags".

\section{REFERENCES}

[1] World Steel Association (2010). Steel Statistical Yearbook 2010. Economics Committee, Brussels

[2] World Steel Association (2018). Steel Statistical Yearbook 2018. Economics Committee, Brussels

[3] Pellegrino C and Faleschini F. (2016). Sustainability Improvements in the Concrete Industry-Use of Recycled Materials for Structural Concrete Production. Green Energy and Technology Series, Springer, Switzerland, 2016 
[4] Muhmood L, Vitta S, Venkateswaran D. (2009). Cementitious and pozzolanic behavior of electric arc furnace steel slags. Cement and Concrete Research, 2009; 39: 102-109

[5] Murphy JN, Meadowcroft TR, Barr PV. (1997). Enhancement of the cementitious properties of steelmaking slag. Canadian Metallurgical Quarterly, 1997; 36: 315-331

[6] Sheen Y, Wang H, Sun T. (2013). A study of engineering properties of cement mortar with stainless steel oxidizing slag and reducing slag resource materials. Construction and Building Materials, 2013; 40: 239-245

[7] Shi C. (2004). Steel slag - its production, processing, characteristics, and cementitious properties. Journal of Materials in Civil Engineering, 2004; 16: 230-236.

[8] lacobescu RI, Koumpouri D, Pontikes Y, Saban R, Angelopoulos GN. (2011) Valorisation of electric arc furnace steel slag as raw material for low energy belite cements. Journal of Hazardous Materials, 2011, 196: 287-294

[9] Matsumoto T, Tobo H, Watanabe K. (2018) Iron and steel slag products and new effective utilization technologies. JFE technical report No. 23, Mar. 2018, 62-68

[10] Brad AS and Roesler JR. (2014). Concrete with steel furnace slag and fractioned reclaimed asphalt pavement. Research Report No. ICT 14-015, Illinois Center for Transportation, USA, available on September 2018 in: https://apps.ict.illinois.edu/projects/getfile.asp?id=3174

[11] Sas W, Gluchowski A, Radziemska M, Dziecid J, Szymánski A. (2015). Environmental and Geotechnical Assesment of the Steel Slag as a Material for Road Structure. Materials, 2015, 8: 4857-4875

[12] Passetto M, Baldo N. (2011). Mix design and performance analysis of asphalt concretes with electric arc furnace slag. Construction and Building Materials, 2011; 25: 3458-3468

[13] Oluwasola OA, Hainin MR, Aziz MMA (2015). Evaluation of asphalt mixtures incorporating electric arc furnace steel slag and copper mine tailings for road construction. Transportation Geotechnies, 2015, 2: 47-55

[14] Wang GC (2016). The utilization of slag in civil infrastructure construction, Woodhead Publishing series in civil engineering Number 68, UK. 
[15] Amaral de Lima L. (1999). Hormigones con escorias de horno eléctrico como áridos: propiedades, durabilidad y comportamiento ambiental. Doctoral Thesis. Universidad Politécnica de Catalunya, Spain, 1999

[16] Sezer GI, Gülderen M.(2015). Usage of steel slag in concrete as fine and/or coarse aggregate. Indian Journal of Engineering \& Materials Sciences, 2015, 22: 339-344

[17] Bäverman C, Aran F. (1997). A study of the potential of utilising electric arc furnace slag as filling material in concrete. In: Waste Materials in Construction. Putting Theory into Practice. Elsevier Science, 1997, 373-376

[18] Qasrawi H, Shalabi F, Ibrahim A. (2009). Use of low CaO unprocessed steel slag in concrete as fine aggregate. Construction and Building Materials, 2009; 23: 1118-1125

[19] Monosi S, Ruello ML, Sani D. (2015). Electric arc furnace slag as natural aggregate replacement in concrete production. Cement and Concrete Composites, 2016, 16: 66-72

[20] Tran M, Nguyen CV, Nawa T, Stitmannaithum B.(2014). Properties of high strength concrete using steel slag coarse aggregate. ASEAN Engineering Journal Part C, 2:22-32.

[21] Abdulaziz I, Al-Negheismish Faisal H, Al-Sugair, Rajeh Z. (1996). Utilization of local steelmaking slag in concrete. Journal of King Saud University-Engineering Sciences, 1996, 9(1): 39-55

[22] Abu-Eishah SI, El-Dieb AS, Bedir MS. (2012). Performance of concrete mixtures made with electric arc furnace (EAF) steel slag aggregate produced in the Arabian Gulf region. Construction and Building Materials, 2012; 34: 249-256

[23] Beshr H, Almusallam AA, Maslehuddin M. (2003). Effect of coarse aggregate quality on the mechanical properties of high strength concrete. Construction and Building Materials, 2003; 17: 97-103

[24] Patel JP (2008). Broader use of steel slag aggregates in concrete. Master's Thesis. Science in Civil Engineering, Cleveland State University, 2008.

[25] Maslehuddin M, Alfarabi M, Sharif MS, Ibrahim M, Barry MS. (2003). Comparison of properties of steel slag and crushed limestone aggregate concretes. Construction and Building Materials, 2003; 17: 105-112

[26] Netinger I, Bjegović D, Vrhovac G. (2011). Utilisation of steel slag as an aggregate in concrete. Materials and Structures, 2011, 44:1565-1575 
[27] Pellegrino C, Gaddo V. (2009). Mechanical and durability characteristics of concrete containing EAF slags as aggregate. Cement \& Concrete Composites, 2009; 31: 663-671

[28] Nitendra Palankar AU, Shankar R, Mithun BM.(2017). Investigations on Alkali-Activated Slag/Fly Ash Concrete with steel slag coarse aggregate for pavement structures. International Journal of Pavement Engineering, 2017, 18(6): 500-512

[29] Arribas I, Santamaría A, Ruiz E, Ortega-López V, Manso JM. (2015). Electric arc furnace slag and its use in hydraulic concrete. Construction and Building Materials, 2015, 90: 68-79 (2015) High performance concrete with electric arc furnace slag as aggregate: Mechanical and durability properties. Construction and Building Materials, 2015, 101: 113-121

[31] Arribas I. (2011). Estudio y diseño de hormigones estructurales basados en la incorporación de subproductos siderúrgicos: viabilidad tecnológica. Doctoral Thesis. Universidad del País Vasco, Bilbao, Spain, 2011

[32] Manso Villalaín JM. (2001). Fabricación de hormigón hidráulico con escorias de horno eléctrico de arco. Doctoral Thesis, Universidad de Burgos, Spain, 2001

[33] Papayianni I, Anastasiou E. (2010). Production of high-strength concrete using high volume of industrial by-products. Construction and Building Materials, 2010, 24: 1412-1417

[34] Polanco JA, Manso JM, Setién J, González JJ. (2011). Strength and durability of concrete made with electric steelmaking slag. ACI Materials Journal, 2011; 108-M22: 196-203

[35] Vázquez-Ramonich E, Barra M. (2001). Reactivity and expansion of electric arc furnace slag in their application in construction. Materiales de Construcción 2001, 51: 137-148

[36] Manso JM, Hernández D, Milagros Losáñez M, González JJ. (2011). Design and elaboration on concrete mixtures using steelmaking slags. ACI Materials Journal 2011; 108-M72: 673-681

[37] Matsunaga H, Tanishiki K, Tsuzimoto K. (2009). Environment-Friendly Block, "Ferroform", Made from Steel Slag. JFE GIHO 2008; 19: 13-17

[38] Etxeberria M, Vázquez E, Marí A, Barra M. (2007). Influence of amount of recycled coarse aggregates and production process on properties of recycled aggregate concrete. Cement and concrete Research 2007; 37: 735-742 

industrial waste as aggregates. International Journal of sustainable built environment, 2015, 4: 378-390.

[40] Manso JM, Polanco JA, Losañez M, González JJ. (2006). Durability of concrete made with EAF slag as aggregate. Cement \& Concrete Composites 2006; 28: 528-534

[41] Pellegrino C, Cavagnis P, Faleshini F, Brunelli K. (2012). Properties of concretes with black/oxidizing electric arc furnace slag aggregate. Cement \& Concrete Composites, 2012; 37 : 232-240

[42] Arribas I, Vegas I, San-José JT, Manso JM. (2014). Durability studies on steelmaking slag concretes. Materials and Design, 2014; 63: 168-176

[43] San-José JT, Vegas I, Arribas I, Marcos I. (2014). The performance of steel-making slag concretes in the hardened state. Materials and Design, 2014; 60: 612-619

[44] Ortega- López V, Fuente-Alonso JA, Santamaría A, San-José JT, Aragón ÁJT. (2018). Durability studies on fiber-reinforced EAF slag concrete for pavements. Construction and Building Materials, 2018; 163: 471-481

761

[45] Santamaría A, Orbe A, San-José JT, González J-J (2018). A study on the durability of structural concrete incorporating electric steelmaking slags. Construction and Building Materials, 2018; 161: $94-111$

[46] Gökalp I, Uz VM, Saltan M, Tutumluer E. (2018). Technical and environmental evaluation of slags as aggregate for sustainable pavement layer applications. Transportation geotechnics, 2018, 14: 61-69.

[47] González-Ortega MA, Cavalaro SHP, Aguado A. (2015). Influence of barite aggregate friability on mixing process and mechanical properties of concrete. Construction and building materials, 2015; 74: 169-175

[48] González Ortega MA. (2015). Comportamiento y diseño de hormigones estructurales con áridos siderúrgicos EAF. Doctoral Thesis, Universidad Politécnica de Cataluña, Spain, 2015

[49] González-Ortega MA, Segura I, Cavalaro SHP, Toralles-Carbonari B, Aguado A, Andrello AC. (2014). Radiological protection and mechanical properties of concrete with EAF steel slags. Construction and building materials, 2014; 51: 432-438 

industries, Resources, Conservation and Recycling, Volume 55, Issue 8, June 2011, Pages 745754 steelmaking dust. T Nonferr Metal Soc 2008;18:202-6.

[52] EN 933-1:2012. Tests for geometrical properties of aggregates - Part 1: Determination of particle size distribution - Sieving method.

[53] Frías M, Sánchez de Rojas MI. (2004). Chemical assessment of the electric arc furnace slag as construction material: Expansive compounds. Cement and Concrete Research, 2004; 34: 18811888

[54] Frías M, San-José JT, Vegas I. (2010). Steel slag aggregate in concrete: the effect of ageing on potentially expansive compounds. Materiales de Construcción, 2010; 60: 33-45

[55] Wang G, Wang Y, Gao Z. (2010). Use of steel slag as a granular material: Volume expansion prediction and usability criteria. Journal of Hazardous Materials, 2010; 184: 555-560

[56] UNE-EN 12350-2:2009. Testing fresh concrete. Part 2: Slump-test

[57] EN 83315:1996. Concret test. Determination of air content of freshly mixed concrete. Methods pressures.

[58] UNE-EN 12390-7:2009. Testing hardened concrete. Part 7: Density of hardened concrete

[59] UNE-EN 12390-3:2009. Testing hardened concrete. Part 3: Compressive strength of test specimens

[60] UNE-EN 12390-13:2014. Testing hardened concrete. Part 13: Determination of secant modulus of elasticity in compression

[61] UNE-EN 12390-8:2009. Testing hardened concrete. Part 8: Depth of penetration of water under pressure

[62] NEN 7345:2004. Leaching characteristics - Determination of the leaching of inorganic component from moulded or monolitic materials.

[63] Comisión Permanente del Hormigón (2008). Instrucción de Hormigón Estructural EHE, EHE08, 

crystalline gypsum as aggregate. Cement and Concrete Research 1984; 14: 225-230

[65] Skalny J, Marchand J, Odler I. (2002). Sulfate attack on concrete. Modern Concrete Technology: Spon Press; 2002

[66] UNE-EN 12390-6:2010. Testing hardened concrete. Part 6: Tensile splitting strength of test specimens

[67] UNE-EN 14630:2007. Products and systems for the protection and repair of concrete structures. Test methods. Determination of carbonation depth in hardened concrete by the phenolphthalein method

[68] UNE-EN 12504-4:2006. Testing concrete. Part 4: Determination of ultrasonic pulse velocity 